\title{
Being Progressive Is Just A Phase: celebrating the uniqueness of progressive aspect under a phase-based analysis
}

\section{Abstract}

The identity of phasal boundaries has mostly been considered in light of minimal CP-TP-vPVP structures. The question this paper addresses is where the clause internal phase boundary lies in light of more complex structures in which aspectual projections intervene between TP and vP. I claim progressive aspect to be unique amongst aspectual forms in English in that it is part of the clause internal phase, whilst perfect aspect and all higher functional items are contained within the $\mathrm{CP} / \mathrm{TP}$ phase. This claim accounts for many peculiar quirks of progressive aspect in English, namely in VP ellipsis, fronting phenomena, idioms and existential constructions.

On the theoretical front I argue that this division in the aspectual hierarchy is best understood through a variable approach to phases in which the highest projection within a sub-numeration acts as the phase, irrespective of what that projection is. This denies $\mathrm{vP}$ of its exclusivity as the clause-internal phase, and allows the progressive layer to project the phase when present. This approach generally sits in line with the move towards a dynamic understanding of phases, as per Bobaljik \& Wurmbrand (2005), Wurmbrand (2012, to appear) and Bošković (to appear $\mathrm{a}, \mathrm{b}$ ).

\section{Introduction}

It has long been observed that certain domains appear to exist in natural language which exhibit syntactic, phonological and semantic independence from the rest of the structure surrounding them. An ongoing issue for generative grammarians has been how these facts should best be captured within a syntactic framework. Various proposals have been made to explain these seemingly opaque domains, such as Chomsky's Barriers (1986) model. The Minimalist Program (Chomsky 1995), however, abandoned such earlier proposals in favour of phase theory (Chomsky 2000, 2001). Under phase theory, the syntactic derivation is essentially built up in a series of discrete chunks of structure, known as phases, rather than forming the entire derivation in one go. Once complete, each phase is sent off independently to $\mathrm{PF}$ and $\mathrm{LF}$ for pronunciation and interpretation, thereby establishing the apparent independence of certain domains. With respect to the main clausal spine, Chomsky (2000, 2001) assumes this to be bifurcated into two discrete phases; the lower phase demarcated by $\mathrm{vP}$, and the higher phase demarcated by CP. The focus of this paper will be on the identity of the lower, clause internal phase.

For the most part, the phasal boundary of the clause internal phase is only ever considered in the context of a minimal $\mathrm{CP}>\mathrm{TP}>\mathrm{vP}>\mathrm{VP}$ structure. ${ }^{1}$ But what happens if we look at phases in the light of more articulated structures? Consider, for instance, the sentence below:

Betsy must have been being paid to keep quiet about the crime. ${ }^{2}$

In this example there is clearly a more detailed structure intervening between TP and vP involving a number of aspectual projections. Phases are rarely explored in the context of these more elaborate structures, and on the few occasions that they have been considered, there has often been confusion as to where the phasal boundary lies. Several authors assume that the entire range of aspectual projections may constitute separate clause internal phases (Butler 2004; Henry \& Cottell 2007; Deal 2009), or, conversely, are simply a part of the higher

\footnotetext{
${ }^{1}$ See, however, Rizzi (2005) and Kidwai (2010) for considerations of phase theory in terms of a cartographical framework.

${ }^{2}$ The data presented in this paper is based on the judgments of a number of native speakers of British English, including those of the author, unless otherwise stated.
} 
TP/CP phase (Chomsky 2000, 2001; Svenonius 2004, 2005). Alternatively, Wurmbrand (2012, to appear) and Bošković (to appear a) claim the entire range of aspectual projections are contained within the one clause internal phase. In short, no consensus has been reached as to where the clause internal phase boundary lies in light of more complex structures.

This paper directly addresses this issue by claiming that the clause internal phase boundary, which under standard minimalist assumptions is $\mathrm{VP}$, may in fact extend as far as the progressive aspectual layer when such projections are present in the structure. Perfect aspect, on the other hand, is always contained within the higher phase of the clause, along with modals, TP and CP. This proposal will be formalised by claiming that the last merged item from a sub-numeration acts as the phase, whatever that last merged item may be. By taking progressive aspect to be contained within the same sub-numeration as the lexical verb (but not perfect aspect), this allows for a variable phase boundary in which progressive aspect, when present in the derivation, acts as the clause internal phase instead of vP. This proposal will be motivated empirically by the peculiar properties that the English progressive aspect exhibits in relation to VP ellipsis, fronting phenomena, idioms and existential constructions.

The rest of this paper is structured as follows: section 2 discusses the formal background to phase theory that I will be following, and also outlines the basic structure of the aspectual hierarchy in English. In section 3 I show how the current understanding of ellipsis in terms of phases predicts that the progressive aspectual layer of the clause should be contained within the clause internal phase, but not the perfect aspectual layer. Section 4 illustrates how Chomsky's (2005), Fowlie's (2010) and Roberts' (2010) claims that only phases can move predicts that the progressive aspectual layer, but nothing higher, should act as the clause internal phase when present, rather than vP. Section 5 discusses how Svenonius' (2005) understanding of idioms as being constrained by phasal domains provides further support for this claim. Section 6 provides a formal explanation for how progressive aspect can constitute a part of the clause internal phase but not perfect aspect. Section 7 seeks further support for this proposal from existential constructions, whilst section 8 deals with any remaining issues. Finally, section 9 concludes.

\section{Background Assumptions}

\subsection{Phase Theory}

Given the various different approaches to phase theory that have been proposed over the last decade (Chomsky 2000, 2001, 2005; Fox \& Pesetsky 2003, 2004; Svenonius 2004; to name but a few), I make clear here the core concepts of phase theory that I will be assuming.

I generally follow the traditional concepts of phase theory as formalised in Chomsky (2000, 2001) where it is claimed that the composition of each phase is determined in the numeration. If one considers a minimal $\mathrm{CP}>\mathrm{TP}>\mathrm{vP}>\mathrm{VP}$ structure, and putting aside arguments, the basic numeration for such a derivation would be comprised as follows:

$$
[\mathrm{C} \mathrm{T} \text { v V] }
$$

However, rather than the numeration being comprised of one single set of items, phase theory assumes a number of smaller sets of items: sub-numerations:

$$
[[\mathrm{C} \text { T] }[\mathrm{v} \text { V]] }
$$

These sub-numerations are what constitute phases. Chomsky $(2000,2001)$ claims that items from the first sub-numeration are merged into the workspace until the point that $\mathrm{v}$ is merged, which is the phase head. Therefore, the phrase that $\mathrm{v}$ projects, $\mathrm{vP}$, is the clause internal phase. Similarly, C from the second sub-numeration is the phase head of the higher phase, meaning the phrase it projects, CP, is the higher phase. These phases are, at some point in the course of the derivation, independently shipped off to PF and LF for spell out and interpretation 
respectively. However, phases are not shipped off in their entirety. Rather, only the complement of the phase head, the spell-out domain, is sent to spell out, whilst the phase head and its specifier, the phase edge, remain in the syntax and are only spelt out with the higher phase.

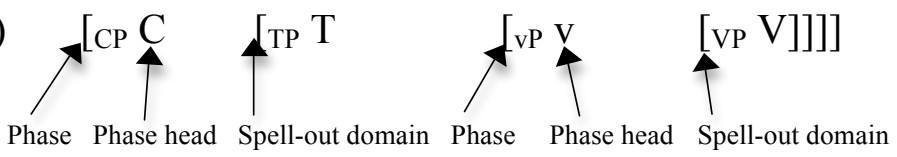

A side effect of all this is that any material contained inside the completed spell-out domain would be unavailable for further syntactic computations. That is, if an item has been shipped off, along with the rest of the spell-out domain, to PF and LF, then it is no longer visible to the syntactic component and so cannot enter into any further syntactic operations with elements outside of the phase; thus deriving the opacity and apparent syntactic, phonological and semantic independence that phases exhibit.

Consequently, any item merged within the spell-out domain of the lower phase that must undergo operations within the higher phase, proceeds first via the phase edge so as to escape spell out of the lower phase and remain visible to the syntax. ${ }^{3}$ This therefore allows such items to undergo syntactic operations within the higher phase.

Finally, I follow Chomsky (2001) in assuming that a domain is sent to spell out, not upon merger of the phase head immediately above it, but upon merger of the phase head of the next phase up. For instance, the VP spell-out domain is only spelt out upon merger of the $\mathrm{C}$ phase head. This can be formalised with the revised version of the Phase Impenetrability Condition (PIC II, Chomsky 2001) as follows:

Given structure [zP Z [XP [HP $\alpha$ [H YP]]]], with $\mathrm{H}$ and $\mathrm{Z}$ the heads of phases - The domain of $\mathrm{H}$ is not accessible to operations at $\mathrm{ZP}$; only $\mathrm{H}$ and its edge $\alpha$ are accessible to such operations.

These are the crucial assumptions of phase theory that I will follow, although I will take issue with the claim that $\mathrm{C}$ and $\mathrm{v}$ are the only elements that may act as phase heads within the matrix clause, and argue that the clause internal phase, when considered in light of more elaborate structure, can be somewhat larger than just vP. ${ }^{4}$ In section 3 I also take issue with the claim that only phasal complements can be sent to spell out and argue that full phasal spell out is also a possibility. In the next section I outline a number of background assumptions with regards to the enriched structure of the aspectual hierarchy in English.

\subsection{Auxiliaries and the aspectual hierarchy}

As Cinque (1999) has observed, there is a universal functional hierarchy of the form: tense $>$ modality $>$ perfect aspect $>$ progressive aspect $>$ voice $>$ verb:

Betsy must have been being paid to keep quiet about the crime. ${ }^{5}$

\footnotetext{
${ }^{3}$ I do not assume, however, that phase edges and phase heads are the only potential landing sites for internal merge, merely that syntactic items must proceed via these positions in order to undergo operations in the higher phase. I also do not assume, as per Chomsky (2005) and Richards (2007), that only phase heads trigger Agree.

${ }^{4}$ As detailed in section 6, I will ultimately be assuming a dynamic approach to phases along the lines of Bobaljik \& Wurmbrand (2005), Wurmbrand (2012, to appear) and Bošković (to appear a,b). An alternative approach to dynamic phases is that of phase extension and phase sliding, as per Den Dikken (2007) and Gallego (2010), respectively. However, I will not be assuming these alternative approaches, at least for the purposes of English.

${ }^{5}$ In this paper I stay away from discussion of infinitival to which goes beyond the scope of this research.
} 
In order to derive this functional hierarchy one must posit a number of additional projections between $\mathrm{TP}$ and $\mathrm{vP}$ whose heads can host the relevant auxiliaries and aspectual forms. Here I follow work done by Cinque (1999), Harwood (2011), Aelbrecht \& Harwood (2013) and Bošković (to appear a), and propose the articulated structure in (7) (leaving specifiers aside for reasons of space and simplicity). The modal, auxiliary and lexical verbs, all written in italics, represent the abstract, uninflected forms of these verbs in their base positions:

(7)

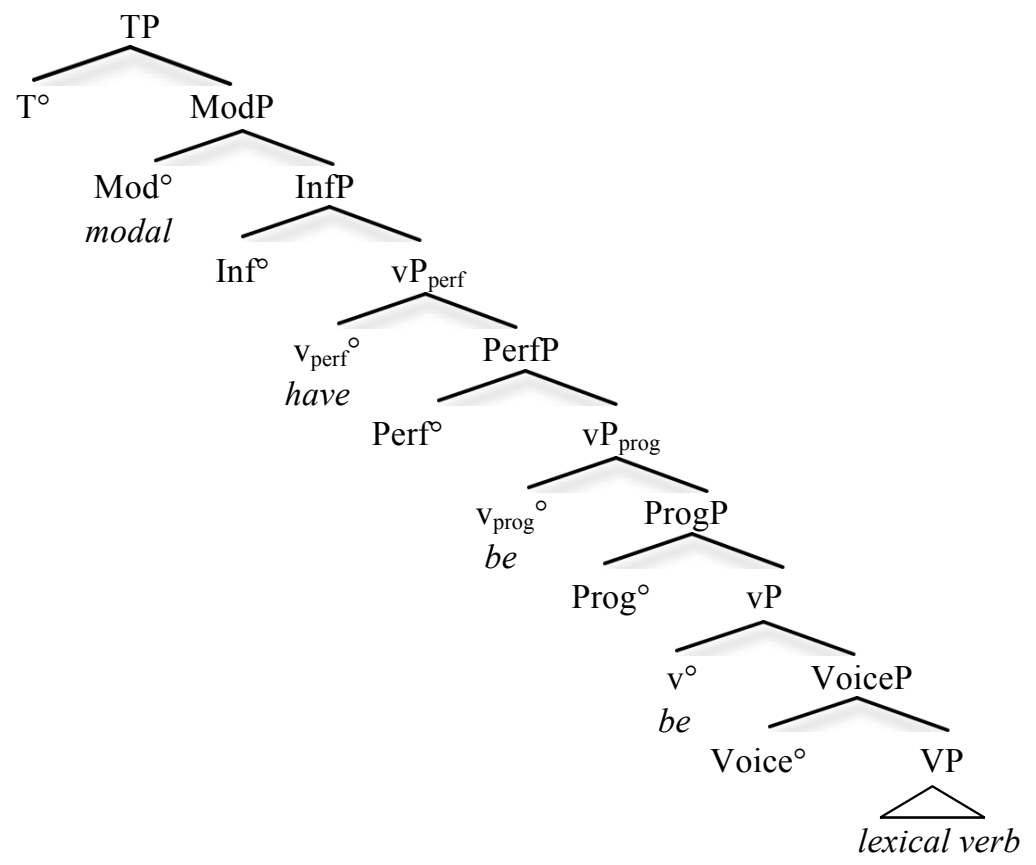

First and foremost I assume a paired layering in which auxiliaries head their own vP shells independent of the aspectual projections that they select for. Whilst this is theoretically less attractive than a system in which auxiliaries head the actual aspectual projections themselves (as in Bjorkman 2011), I assume that auxiliaries raise for inflectional purposes (see later), which means that first merger of auxiliaries in their own $\mathrm{vP}$ shells is necessary in order to prevent auxiliaries from raising into one another's trace positions, a clear violation of locality.

Starting with the modal layer, I assume modals to be merged in ModP, which immediately selects for the infinitival phrase InfP, licensing the infinitival forms of lower verbs. Below this is the perfect aspect layer. This layer is composed of $\mathrm{vP}_{\text {perf, }}$ headed by the perfect auxiliary have, followed by the aspectual phrase PerfP, which licenses the perfect forms of lower verbs. Following this is the progressive layer: $\mathrm{vP}_{\text {prog}}$, headed by the progressive auxiliary be, which selects the progressive aspectual phrase, ProgP, licensing the progressive forms of lower verbs. I follow Baker (1997), Eide \& Åfarli (1997), Bowers (2002), Harwood (2011) and Aelbrecht \& Harwood (2013) in assuming that passive and copula be are both merged in $\mathrm{v}^{\circ}$ and that VoiceP, which determines the active or passive voice of the sentence, is situated between vP and VP. ${ }^{6}$

Furthermore, I assume a What You See Is What You Get (WYSIWYG) approach to the functional hierarchy: the relevant verbal and aspectual projections are only ever present in the underlying derivation if the aspectual meaning is expressed by the clause. TP and VP are taken to always be present, ${ }^{7}$ but ModP, InfP, $\mathrm{vP}_{\text {perf }}$, PerfP, $\mathrm{vP}_{\text {prog }}$ and $\mathrm{ProgP}$ are only present if modals, perfect aspect or progressive aspect, respectively, are expressed in the sentence.

\footnotetext{
${ }^{6}$ The assumption that passive and copula be reside in $\mathrm{v}^{\circ}$ is not pivotal for the story. An approach in which passive be is merged in its own $\mathrm{vP}_{\text {voice }}$ projection, which is followed by VoiceP, and only then by $\mathrm{vP}$ proper, is also possible, and would not affect the analysis.

${ }^{7}$ Unless we have a copular construction in which case VP is replaced by NP, AdjP or PP.
} 
Whether projections such as VoiceP and vP are always present is a matter for debate and one which I will largely set aside for the majority of this paper. See section 6, however, for a brief discussion of this issue in relation to phase theory.

Moreover, I take auxiliaries to uniformly raise for inflectional purposes. Specifically, I suppose that auxiliaries raise for reasons of feature checking, as per Chomsky (1993), Lasnik (1995b), Baker (2003) and Aelbrecht \& Harwood (2013). That is, auxiliaries enter the derivation bearing readily valued, but uninterpretable inflectional features that must raise to either $\mathrm{T}^{\circ}$, Inf ${ }^{\circ}$ or an aspectual head in order to have this feature checked by a matching interpretable feature, thereby licensing the auxiliary's form at PF. ${ }^{8}$ Let us briefly consider what this implies for the distribution of auxiliaries.

I assume that, when realised as being, passive or copula be bears an uninterpretable inflectional feature $[u \mathrm{~T}]$ valued for progressive aspect: [uT:Prog]. In order to check this feature, being raises out of $\mathrm{v}^{\circ}$ to $\operatorname{Prog}^{\circ}$, which bears a matching interpretable feature of the form [iT:Prog]. Once in $\operatorname{Prog}^{\circ}$, being is able to check its feature and is spelt out in this position in accordance with its feature value:

(8)

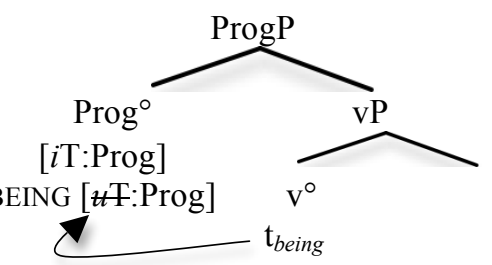

Been on the other hand, whether progressive, passive or copular, bears an uninterpretable inflectional feature valued for perfect aspect [uT:Perf], causing it to raise out of $\mathrm{v}^{\circ} / \mathrm{v}_{\text {prog }}{ }^{\circ}$ to Perf ${ }^{\circ}$ in order to check this feature. Be raises from $\mathrm{v}^{\circ} / \mathrm{v}_{\text {prog }}{ }^{\circ}$ to check its uninterpretable infinitival [ $u \mathrm{~T}$ :Inf] feature in $\operatorname{Inf}^{\circ}$, whilst finite be raises out of $\mathrm{v}^{\circ} / \mathrm{v}_{\text {prog }}{ }^{\circ}$ to check its [ $u \mathrm{~T}:$ Fin] feature in $\mathrm{T}^{\circ}$. Non-finite have raises out of $\mathrm{v}_{\text {perf }}{ }^{\circ}$ to $\operatorname{Inf}^{\circ}$ to check its infinitival [uT:Inf] feature, and to $\mathrm{T}^{\circ}$ when finite and bearing a $[u \mathrm{~T}:$ Fin] feature. Finally, modals always raise from $\operatorname{Mod}^{\circ}$ to $\mathrm{T}^{\circ}$ to check their $[u \mathrm{~T}:$ Fin] feature.

This gives us the distribution of auxiliaries in (9), where the italicised forms represent the base positions of auxiliaries in their abstract uninflected forms, and the capitalised forms are their spell-out positions:

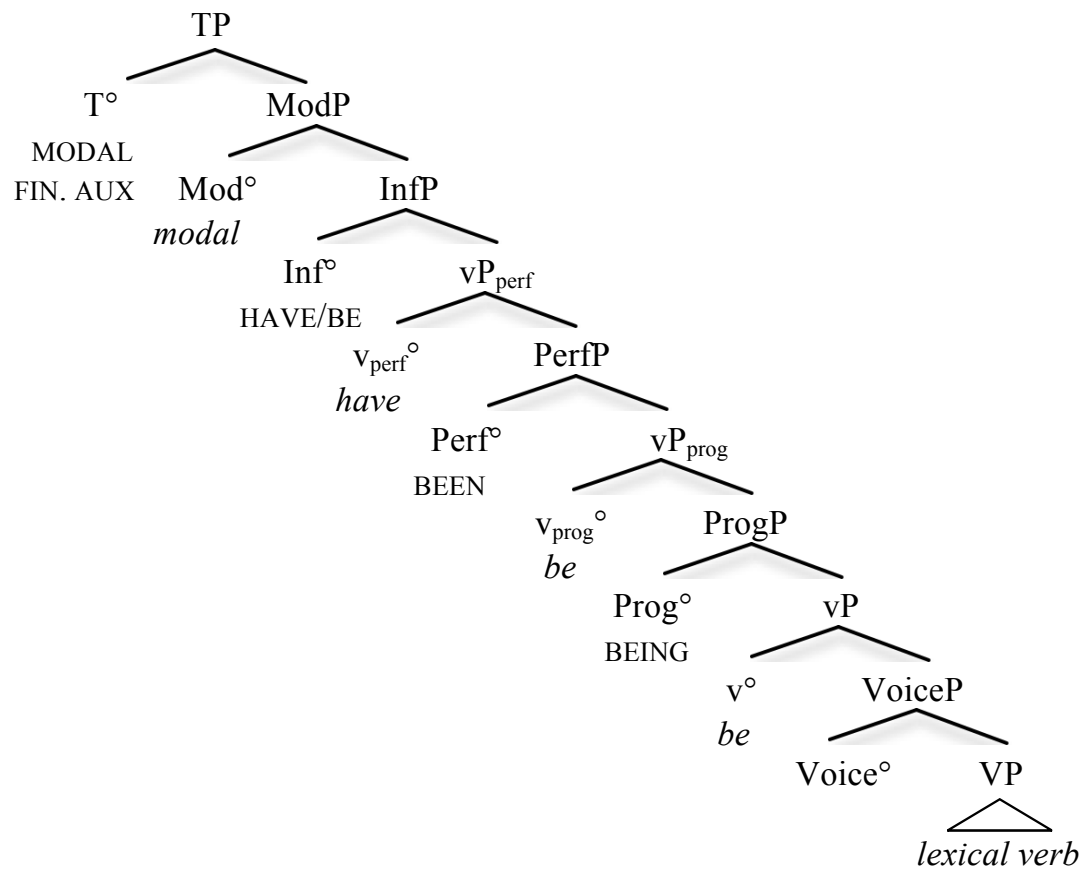

\footnotetext{
${ }^{8}$ This results in a system in which movement of the auxiliary is driven by a featural deficiency on the moving element itself. See Bošković's (2007) theory of foot driven movement for an understanding of how this can occur under current Minimalist assumptions.
} 
I follow Chomsky (1993, 1995), Lasnik (1995b) and Aelbrecht \& Harwood (2013) in assuming that such auxiliary head movement is syntactic, but that its output is generally a concern for the PF interface, not necessarily the LF interface. That is, the uninterpretable inflectional features on the auxiliaries which cause them to raise to higher aspectual heads must be checked before spell out at PF, otherwise a derivational crash at PF would ensue. The implication is therefore that the raising and checking of auxiliaries must occur overtly in the syntax rather than covertly in order for the morphological form of the auxiliary to be licensed. This is not controversial. All overt raising of elements is standardly considered to be in order to satisfy a requirement at the PF interface. And since verb raising typically does not carry semantic import, it is logical that such movement should not be a part of the LF interface. ${ }^{9}$

Finally, it is standardly assumed that in English the lexical verb does not raise out of the vP domain. I do not commit myself to any particular approach as to how the lexical verb is inflected, though most proposals that have been made in this field, such as some form of covert raising (Chomsky 1993, 1995) or merger under PF adjacency (Marantz 1988; Bobaljik 1994; Lasnik 1995b; Baker 2003) are compatible under the assumptions made so far.

Having outlined the background assumptions to phase theory and the enriched structure of the auxiliary and aspectual system, the following three sections discuss the empirical phenomena that lead us to postulate that as much as progressive aspect should be included within the clause internal phase.

\section{Ellipsis and Phases}

In this section I discuss the claims that ellipsis is constrained by phases and show that, when applied to VPE and the English auxiliary paradigm, progressive aspect is included within the clause internal phase. ${ }^{10}$ In section 3.1 I discuss the background literature on ellipsis and phases and conclude, as per Bošković (to appear a), that ellipsis may target either the phasal complement or the entire phase. In 3.2 I abstract away from phase theory and focus on the size of the ellipsis site in English VPE, claiming, as per Aelbrecht \& Harwood (2013), that VPE targets the progressive aspectual layer. Finally, in section 3.3 I discuss the implications that the conclusions from the previous sections have on the size of the clause internal phase.

\subsection{Background}

This section discusses the previous literature which argues that ellipsis is constrained by phases. Ultimately I adopt Bošković's (to appear a) claim that ellipsis may privilege either the phasal complement, or the entire phase.

\subsubsection{Ellipsis as non-pronunciation of the phasal domain}

Ellipsis is the apparent deletion of certain domains of syntactic structure. English VP Ellipsis (VPE), for instance, involves deletion of the lexical verb and its internal arguments:

$$
\text { Apollo punched Rocky, and Mr. T did [punch Rocky] too. }
$$

I follow numerous authors (Ross 1969; Chomsky 1972; Sag 1976; Tancredi 1992; Chomsky \& Lasnik 1993; Lasnik 1995a, 1999, 2001b; Merchant 2001, 2004; Aelbrecht 2010) in assuming that ellipsis phenomena such as VPE are deletion of syntactic structures at PF.

A long-standing issue with ellipsis phenomena has been why only certain constituents are targeted by ellipsis. Gengel $(2007,2008)$ suggests a potential solution to this problem by

\footnotetext{
9 The term 'uninterpretable' features usually conjures up associations with LF rather than PF. I use 'uninterpretable' here, however, for want of a better term that refers to PF features. It is also possible that the auxiliaries' inflectional features must similarly be checked at the LF interface, but this can occur covertly in the syntax. The important point is that the overt raising and checking of auxiliaries' inflectional features is a concern for the PF interface to license the morphological forms that the auxiliaries occur in.

${ }^{10}$ This paper has nothing to say, however, about the licensing requirements on ellipsis.
} 
connecting ellipsis sites to phasal spell-out domains. That is, Gengel $(2007,2008)$ observes that ellipsis sites appear to correspond to spell-out domains. This is most clearly illustrated in sluicing (Ross 1969; Saito \& Murasugi 1990; Merchant 2001), which is the ellipsis of TP:

Pinocchio lied about something, but I don’t know [

Under the standard approach to phase theory, $\mathrm{C}^{\circ}$ is a phase head and TP is the spell-out domain. Therefore, ellipsis in (11) appears to target the spell-out domain of the CP phase. ${ }^{11}$

VPE can also be analysed as non-pronunciation of the spell-out domain of the clause internal phase. VPE has traditionally been analysed as deletion of VP (Akmajian \& Wasow 1975; Sag 1976; Akmajian Steele \& Wasow 1979; Lasnik 1999, 2001b, Gengel 2007, 2008), containing the lexical verb and its internal arguments. If $v \mathrm{P}$ is the clause internal phase and $\mathrm{v}^{\circ}$ the phase head, as Chomsky $(2000,2001)$ claims, then VP is the spell-out domain (under a minimal C-T-v-V structure), and hence the ellipsis site.

According to Gengel $(2007,2008)$, the elided constituent is always that part of the phase which is shipped off from the syntax, namely the phasal complement. This makes sense intuitively: a completed phase ships off its complement to PF and LF for pronunciation and interpretation. With regards to ellipsis, all that needs to be said is that, at PF, one chooses to either pronounce or not pronounce the spell-out domain. So ellipsis is essentially nonpronunciation of the phasal spell-out domain. Crucially then, ellipsis is constrained by phases, in that it only ever targets phasal complements. This approach has been assumed by van Craenenbroeck (to appear), Rouveret (2006, 2011, 2012), Gallego (2010), Sailor (2012), Wurmbrand (2012) and Bošković (to appear a).

\subsubsection{The complement or the entire phase?}

However, as Bošković (to appear a) notes, the facts are not quite as simple as they at first appear. It has been claimed that Japanese, Korean, Turkish, Chinese and American Sign Language all allow for full argument ellipsis (Oku 1998; Kim 1999; Saito 2001, 2004, 2007; Tomioka 2003; Sugawa 2008; Sener \& Takahashi 2010; D. Takahashi 2008a, b, 2010; Bošković 2011; Koulidobrova 2011; Takita 2011a, b; cited in Bošković to appear a). This is illustrated below for Japanese: ${ }^{12}$
a. Taroo-wa sannin-no sensei-o sonkeisiteiru.
Taro-TOP three-GEN teacher-ACC respects.
'Taro respects three teachers.'
b. Hanako-mo e sonkeisiteiru.
Hanako-also respects.
'Hanako respects e, too.'

(Sener \& Takahashi 2010, cited in Bošković to appear a:(30))

Saito (2007), D. Takahashi (2010) and Bošković (to appear a) all additionally observe that Japanese allows for DP, CP and PP argument ellipsis. If CPs, DPs and PPs act as phases, as assumed by Chomsky (2000, 2001, 2005), Fowlie (2010), Koopman (2010), Aelbrecht \& Den Dikken (to appear) and Bošković (to appear a, b), then the aforementioned data imply that ellipsis can also target the entire phase rather than just the complement of the phase head. ${ }^{13}$ Indeed, Holmberg (1999, 2001), Fox \& Pesetsky (2003), Aelbrecht (2012) and Bošković (to

\footnotetext{
${ }^{11} \mathrm{NP}$ ellipsis is another possible instance of ellipsis targeting the phasal complement if one assumes, as per Chomsky (2005), that DPs constitute phases.

12 As Sener \& Takahashi (2010) and Bošković (to appear a) note, the sentence in (12)b can have a sloppy interpretation which is only possible under an ellipsis analysis and not under a null pronoun/object drop analysis. ${ }^{13}$ Chomsky $(2000,2001,2005)$ does not actually explicitly assume PP to act as a phase, though the rest of the aforementioned authors do.
} 
appear a) have claimed that ellipsis targets entire phases. Going one step further, Bošković (to appear a) has claimed that ellipsis is constrained by phases in that only either the phasal complement or the entire phase can be elided. That is, there is a degree of parametric variation as to whether ellipsis privileges the one or the other. This choice can differ crosslinguistically, as well as between types of ellipsis within any one language. ${ }^{14}$

Bošković (to appear a) elaborates an argument involving extraction data in support of the claim that ellipsis can privilege either the phasal complement or the entire phase. Here I review his argumentation. First of all, note there is an implication that, if an entire phase can be elided and ellipsis only targets that part of the phase which is spelt out, then spell out of an entire phase is sometimes possible. ${ }^{15}$ Recall furthermore that, in order for elements generated within the lower phase to undergo operations within higher phases, they must first proceed via the phase edge in order to escape spell out. Recall also that PIC II (Chomsky 2001) is assumed according to which spell out within a lower phase does not occur until the phase head of the higher phase has been merged. For instance, in a minimalist C-T-v-V structure, spell out from the vP phase does not occur until $\mathrm{C}^{\circ}$ is merged. Bošković (to appear a) notes that these assumptions make an interesting prediction, namely that extraction from a phase should be more restricted if the entire phase is spelt out as opposed to the phasal complement.

Consider, for instance, the extraction possibilities under a minimal C-T-v-V structure in which $\mathrm{C}$ and $\mathrm{v}$ are phase heads, and the items $\alpha$ and $\beta$ represent an agentive subject and a whobject, respectively. Upon completion of the $\mathrm{vP}$ phase, $\alpha$ and $\beta$ raise to the specifiers of $\mathrm{vP}$ (if they do not occupy this position already):

$$
\left[\mathrm{vP} \beta \alpha\left[\mathrm{v}\left[\mathrm{vP}\left[\mathrm{Vt}_{\beta}\right]\right]\right]\right]
$$

Once TP is merged, the agentive subject $\alpha$ raises to the canonical subject position of Spec-TP:

$$
\left[\mathrm{TP} \alpha\left[\mathrm{T}^{\circ}\left[{ }_{\mathrm{vP}} \beta \mathrm{t}_{\alpha}\left[\mathrm{v}\left[\mathrm{vP} \mathrm{Vt}_{\beta}\right]\right]\right]\right]\right]
$$

Merger of $\mathrm{C}^{\circ}$, the next phase head, instantly triggers spell out of the lower phase. At this point the syntax is presented with a choice: to either spell out the phasal complement, or the entire phase. Consider what would happen in each instance. If the phasal complement, VP, was spelt out, $\mathrm{v}$ and its specifiers would survive spell-out. Therefore the wh-object, $\beta$, remains in the derivation and can undergo movement to Spec-CP (I grey out the constituent that has been sent to spell-out):

$$
\left[\mathrm{CP} \beta\left[\mathrm{C}\left[\mathrm{TP}_{\mathrm{TP}} \alpha \mathrm{T}^{\circ}\left[\mathrm{vp}_{\mathrm{p}} \mathrm{t}_{\mathrm{\alpha}}\left[\mathrm{v}\left[\mathrm{VP} \mathrm{V} \mathrm{t}_{\beta}\right]\right]\right]\right]\right]\right.
$$

If, on the other hand, the entire lower phase, including the phase head and edge, was spelt out, then the wh-object, $\beta$, would also be sent to spell-out and hence would be unavailable for further syntactic computations. The result therefore is that $\beta$ would be unable to extract from the lower phase and raise to Spec-CP: ${ }^{16}$

\footnotetext{
${ }^{14}$ It should be noted that, under this analysis, ellipsis can never target any other constituent, such as the complement of the complement of a phase head.

${ }^{15}$ Indeed, Fox \& Pesetsky (2003, 2005), Svenonius (2004, 2005), Fowlie (2010), Richards (2011) and Aelbrecht (2012) have all argued for full phasal spell-out. See section 3.1.4 for a formalisation of how spell out of the phasal complement or the entire phase can occur.

${ }^{16}$ It has of course been argued that all operations triggered by a single head, e.g. $\mathrm{C}^{\circ}$, happen simultaneously (Chomsky 2005, Richards 2007). Therefore, spell out and movement of the operator to Spec-CP would occur at the same time and no restrictions on extraction would occur. This is not the case with PIC II (Chomsky 2000), however, in which spell out triggered by $\mathrm{C}^{\circ}$ must precede any other operations related to $\mathrm{C}^{\circ}$, otherwise the spellout domain of the clause internal phase would be visible to $\mathrm{C}^{\circ}$.
} 
Crucially, extraction of elements from the clause internal phase into the higher phase should always be possible. The difference is that spell out of the entire lower phase should make extraction difficult for elements moving into the specifier of the $\mathrm{C}$ phase head, or positions beyond that. When only the lower phasal complement is spelt out, however, and the phase head and edge survive, all kinds of extraction are predicted to be possible.

In other words, movement from the clause internal phase into the TP domain, hereby referred to as low movement, is always predicted to be possible out of phases. Under spell out of the entire phase, however, movement from the clause internal phase into the CP domain and beyond, hereby referred to as high movement, becomes problematic. So when high movement occurs, we can take this to be an indication that only the phasal complement has been sent to spell out. However, if high movement is disallowed, we can take this to be an indication that the entire phase has been sent to spell out. ${ }^{17}$ One such instance in which the entire phase is shipped off is under certain ellipsis phenomena wherein an entire phase is apparently elided, as reviewed above. As it so happens, Bošković (to appear a) notes that in these cases, high movement is not permitted. Shinohara (2006) and Saito (2007), for instance, observe that A'-extraction is disallowed out of argument ellipsis sites in Japanese:

(17) * Sonohon-o $\mathrm{i}_{\mathrm{i}}$ Taroo-wa [CP Hanako-ga $t_{\mathrm{i}}$ katta to] itta si, that book-ACC Taroo-TOP [CP Hanako-NOM bought that] said and, sono hon- $\mathrm{o}_{\mathrm{j}} \quad$ Ziroo-mo ø itta.

that book-ACC Ziroo-also ø said.

'Taroo said that Hanako bought that book, and Ziroo also said that she bought that book.' $\quad$ (Shinohara 2006 and Saito 2007, cited in Bošković to appear a:(36))

This provides further support for the claim that, under certain circumstances, entire phases can be shipped off from the syntax and elided, rather than just the phasal complement.

English also appears to exhibit instances of ellipsis in which entire phases can be elided. Baltin (2006, 2007, 2012) and Aelbrecht (2010) have noted that British English do does not allow wh-object (high movement) extraction out of the ellipsis site:

$$
\begin{aligned}
& \text { * Although I don't know who Thomas will visit, I do know who Aga will do [visit } \\
& t_{\text {(Baltin 2012:(14)) }}
\end{aligned}
$$

Bošković (to appear a) has analysed this as ellipsis of the full vP phase. ${ }^{18}$ This is contrasted with VPE in which wh-object extraction from the ellipsis site is allowed:

$$
\text { Although I don't know who Thomas will visit, I do know who Aga will [ } \text { visit }_{t_{\text {whe }}} \text { ]. }
$$

Therefore VPE may be analysed as ellipsis of the phasal complement, demonstrating that the choice of whether to elide the entire phase or just the phasal complement can vary within any one language. Bošković (to appear a) further claims that the choice of whether to elide the entire phase or just the phasal complement can even vary within a single type of ellipsis, and that VPE in English is one such instance. I will follow this assumption. Next I provide novel evidence in support of Bošković's (to appear a) claim.

\footnotetext{
17 This is obviously not the only restriction on high movement, since locality considerations and island constraints also have an effect.

${ }^{18}$ See, however, Aelbrecht (2010) and Baltin (2012) for accounts of ellipsis extraction data which argue against a (necessarily) phasal approach to ellipsis.
} 


\subsubsection{New evidence for full phasal ellipsis}

We have already seen above that generally VPE privileges the phasal complement. Evidence from existential constructions, however, demonstrates that VPE can also sometimes target the entire phase. Consider the distribution of the derived subject of a passive existential:

There were several men arrested for drunkenness.

In this sentence the expletive there appears to be occupying Spec-TP, preventing the derived subject from raising to this position. However, given that the derived subject is not occupying its base, post-verbal position, but occurs pre-verbally, some form of intermediate raising must have taken place. Chomsky $(2000,2001)$ analyses this sort of construction as involving stranding of the subject on the clause internal phase edge. Essentially, the derived subject raises to the clause internal phase edge so that it can enter into Case checking relations in the higher phase. ${ }^{19}$ However, merger of expletive there into Spec-TP satisfies the EPP on $\mathrm{T}^{\circ}$ and blocks further raising of the subject, which must then have its Case features checked through non-local Agree. The derived subject is thus stranded on the edge of the clause internal phase where it precedes the lexical verb. ${ }^{20}$ This analysis can be extended to other types of existentials as well, such as unergative and transitive existentials and certain types of unaccusative existentials.

Returning to phases and ellipsis, but with the aforementioned analysis of existentials in mind, it is interesting to note that when VPE is applied to an existential construction, the subject does not escape ellipsis:

(21) John said there were several people arrested last night, and indeed there were (*several people) arrested.

If ellipsis could only target phasal complements, and if the subject of an existential construction occupies the clause internal phase edge, as has been argued, then one would expect the subject to survive ellipsis. Given that the subject is instead included in the ellipsis site suggests that the entire phase can undergo ellipsis. Moreover, recall that when an entire phase has been elided, high movement becomes problematic. In light of this, it is remarkable, but expected under the approach I adopt, that whilst $w h$-movement is perfectly acceptable out of a non-elliptical existential construction, such extraction is impossible under VPE:

a. I don't know what there were so many people getting worked up about $t_{\text {what }}$.

b. * I don't know what there were so many people getting worked up about yesterday, but I do know what there were [so many people getting worked up about $t_{\text {what }}$ last week.

This is quite compelling evidence that VPE, whilst generally privileging the phasal complement of the clause internal phase, can sometimes target the entire phase. ${ }^{21}$

\subsubsection{Formalising the choice between phase and phasal complement}

As was noted in the previous section, if ellipsis only ever targets spell-out domains, and entire phases can sometimes be elided, then an entire phase must sometimes, but not necessarily always, act as a spell-out domain. Here, I offer a tentative explanation as to how full phasal

\footnotetext{
${ }^{19}$ Despite postulating raising to the edge of this phase, Chomsky (2001) actually assumes the clause internal phase in passive constructions to be a weak phase, though Legate (2003) has shown the clause internal phase to always be strong, even with passives and unaccusatives.

${ }^{20}$ See section 7 for a more thorough discussion of existential constructions and phases.

${ }^{21}$ This observation is difficult to explain under more standard, non-phasal accounts of ellipsis extraction data, which predict VPE to uniformly allow for all kinds of extraction.
} 
spell out is sometimes possible, though a thorough explanation is beyond the scope of this article and is a matter for future research. A potential solution is to elaborate on an idea suggested in Bobaljik \& Wurmbrand (2005) where it is claimed that phase heads are in fact domains of overlap between two phases. That is, the phase head of the lower phase is simultaneously selected by the lower phase and the higher phase, meaning that the two phases overlap at this point, as is shown in (23):

(23)

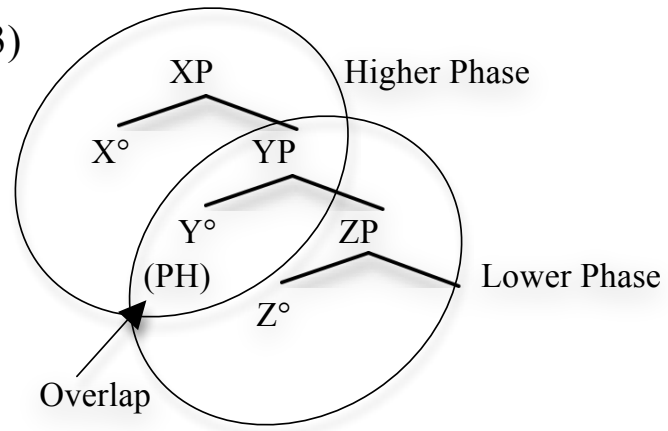

This implies that phase head $\mathrm{Y}$ in fact shares properties with both the lower and the higher phase. The upshot of this is that there is a degree of optionality as to when Y is spelt out. It may spell out with the higher phase as traditionally assumed, thus acting as an escape hatch for movement out of the lower phase, or it may spell out with the lower phase, resulting in full phasal spell out, which would allow us to explain how entire phases can sometimes be targeted by ellipsis. Exactly how the derivation chooses when to spell out the phase head is as yet not entirely clear. This remains a point of further research.

To summarise this section, discussion of the literature on phases and ellipsis has led us to the conclusion that, as claimed by Bošković (to appear a), ellipsis can privilege either the phasal complement, or the entire phase, and that this can differ cross-linguistically, within any one language, and even within a single type of ellipsis. This was evidenced by full argument ellipsis in various languages, ellipsis of the subject on the phase edge in English existentials, and certain restrictions on extraction. It is not yet entirely clear nor predictable when ellipsis targets the phasal complement or the entire phase, but both options appear to be possible.

In section $3.2 \mathrm{I}$ abstract away from phase theory and discuss the size of the ellipsis site in English VPE. In section 3.3 I bring together the conclusions from the previous two sections to argue that progressive aspect should be contained within the clause internal phase in English.

\subsection{The VP Ellipsis site}

\subsubsection{Deletion of being as a first clue}

VPE has often been analysed as deletion of VP or vP (Akmajian \& Wasow 1975; Sag 1976; Akmajian Steele \& Wasow 1979; Lasnik 1999, 2001b; Johnson 2001, 2004; Merchant 2001, 2008, to appear; Gengel 2007, 2008; Aelbrecht 2010), containing the lexical verb and its internal arguments. However, the facts are not quite so simple. When the full range of auxiliaries is considered, we see that it is not just the lexical verb that is elided. Akmajian \& Wasow (1975) and Sag (1976) both noted that the passive and copular auxiliary being is also obligatorily elided under VPE:
a. Goofy was being chastised, and Pluto was (*being) chastised, too.
(passive)
b. Goofy was being annoying, and Pluto was (*being) annoying, too.
(copular)

If the passive and copular auxiliaries are obligatorily elided under VPE when they have raised into the progressive layer for inflectional purposes (recall that I assume being to raise to $\operatorname{Prog}^{\circ}$ ), then the ellipsis site must be somewhat larger than previously assumed, extending as far as the progressive layer. 
It has been claimed, however, by Lobeck (1987), Bošković (2004, to appear a), Thoms (2011) and Sailor (2012), in the spirit of Akmajian \& Wasow (1975), Akmajian, Steele \& Wasow (1979) and Iwakura (1977), that the obligatory ellipsis of being should instead be understood as non-raising of being out of $\mathrm{v}^{\circ}$, and for VPE to therefore be ellipsis of $\mathrm{vP}$. This obviously excludes VPE eliding only as much as VP, but it allows us to hold on to the notion that VPE targets vP.

The problem with claiming that being does not raise out of $\mathrm{v}^{\circ}$ is that it is a stipulation. Akmajian \& Wasow (1975), Akmajian, Steele \& Wasow (1979), Iwakura (1977), Lobeck (1987), Bošković (2004, to appear a), Thoms (2011) and Sailor (2012) all assume uniform raising of all other auxiliaries except for being without any due motivation for this exception. $^{22}$ The only evidence put forward in favour of this claim is the fact that floating quantifiers (FQs) cannot follow being:
a. We were $<$ all $>$ being $<*$ all $>$ expelled.
b. We were $<$ all $>$ being $<*$ all $>$ rather annoying.

According to Sportiche (1988) and Shlonsky (1991), FQs are adjoined to subjects in their base positions and can be stranded there when the subject raises out. If subjects are merged in Spec-vP, and being remains in $\mathrm{v}^{\circ}$, then we have an instant explanation for why all must precede being: FQs are merged above being, and being never raises over them. However, this argument is only potentially applicable to (25)b. In (25)a the subject is the derived subject of a passive verb, meaning it originated as the complement of $\mathrm{V}^{\circ}$. If floating quantifiers truly represented the base positions of subjects, we would expect the floating quantifier to appear in post-verbal position. As Sportiche (1988), Bobaljik (2001), Bošković (2004) and Cirillo (2009) note, however, all cannot so easily float in post-verbal position:

*We were being expelled all.

Therefore, if all is not found in the base position of the derived subject, it is not entirely clear which position all is occupying when it appears to the left of being. This furthermore implies that we also cannot be entirely certain whether all in the copular construction in (25)b is occupying its base position. Hence the data in (25) cannot conclusively show that being remains in $\mathrm{v}^{\circ}$.

In what follows I review evidence provided by Aelbrecht \& Harwood (2013) (A\&H) which demonstrates that the progressive layer is indeed included in the ellipsis site in VPE. This gives a principled explanation for why being is obligatorily elided without needing to stipulate non-raising of this auxiliary: being raises into the progressive layer of the clause, but this is still included within the ellipsis site. Therefore it never escapes ellipsis.

In order to demonstrate empirically that the progressive aspectual layer should be included in the ellipsis site of English VPE, A\&H turn to an additional observation of Sag's (1976), namely that certain other non-finite auxiliaries may be optionally elided under VPE:

a. Roger has been framed, and Nixon has (been) framed, too.

b. Roger will be framed, and Nixon will (be) framed, too.

\subsubsection{Optional auxiliary ellipsis: auxiliary be}

There have been numerous attempts to explain the optional ellipsis data, but the different analyses can essentially be divided into two approaches: optional extension of the ellipsis site

\footnotetext{
${ }^{22}$ Sailor (2012) actually assumes the opposite of this. That is, he posits uniform non-raising of all non-finite auxiliaries, though he then stipulates raising of be and been without any motivation, essentially rendering his analysis subject to the same criticism.
} 
(Akmajian, Steele \& Wasow 1979; Bošković to appear a), or optional raising of the auxiliaries (Aelbrecht \& Harwood 2013; Sailor 2012; Thoms 2012). However, irrespective of which analysis one chooses, the common consensus is that for an auxiliary to be optionally elided it must have, at the very least, been merged inside the ellipsis site.

I show in this section, following $\mathrm{A} \& \mathrm{H}$, that the only auxiliaries that can uncontroversially be elided are those which are first merged within or below the progressive layer, i.e., the progressive, passive and copular auxiliaries. Section 3.2.3 shows that auxiliaries generated above the progressive layer, i.e., perfect have, cannot so easily be elided. ${ }^{23,24}$ This suggests VPE targets the progressive layer.

First of all, it is quite clear and fairly uncontroversial that both passive and copular auxiliaries can be elided. This is evidenced by the obligatory ellipsis of being illustrated in (24) above, and by the optional ellipsis of be and been (see (27) above for the passive auxiliary and (28) below for the copular auxiliary). ${ }^{25}$ If the passive and copular auxiliaries are merged in $\mathrm{v}^{\circ}$, this shows that at least as much as $\mathrm{vP}$ is elided under VPE.

(28) a. Betty has been in the garden, and Sam has (been) in the garden, too.

b. Betty will be in the garden, and Sam will (be) in the garden, too.

A\&H note that progressive be, merged in the progressive layer, is more complicated. Generally it looks like the progressive auxiliary, when realised as be or been, can be elided:

a. Roger will be questioning our motives, but Peter won't (be).

b. Roger has been questioning our motives, but Peter hasn't (been).

However, when progressive be or been is elided, it is not absolutely clear what is contained within the elided constituent. The elided phrase is assumed to be be/been questioning our motives, but a mismatch interpretation is also available in which progressive aspect is entirely absent and the elided constituent is in fact [question/questioned our motives]. This mismatch interpretation masks whether the progressive auxiliary can truly be elided.

A\&H claim, however, that there is a means of showing that progressive be/been can genuinely be elided. Deal (2009) and Harwood (2011) have both observed that unergative existential constructions are dependent upon progressive aspect: ${ }^{26}$

a. There were several hippos dancing.

b. * There have several hippos danced.

If we apply ellipsis to an unergative existential construction, we can be certain as to the presence of progressive aspect in the underlying structure. That is, there is no potential aspectual mismatch interpretation available to mask the ellipsis of the progressive auxiliary. In such constructions, we see that the progressive auxiliary can indeed be optionally elided: ${ }^{27}$

\footnotetext{
${ }^{23}$ It is a well-known fact of English that modals also cannot be elided under VPE. Therefore there is no need to enter into any discussion of this issue.

${ }^{24}$ Another way of looking at this is to say that forms of be can be elided, whilst other types of auxiliaries cannot so easily elide.

${ }^{25}$ Cases in which been and be are elided give the impression that something larger is elided, such as PerfP or InfP, the heads of which these auxiliaries raise to. I argue, however, that this is an illusion. As will be demonstrated later, I take optional ellipsis of such auxiliaries to be due to optional raising of these auxiliaries out of the ellipsis site and not necessarily due to optional extension of the ellipsis site to include PerfP or InfP.

${ }^{26}$ The same restriction holds for transitive and ditransitive existential constructions as well.

${ }^{27}$ It has been argued in the literature (Williams 1984; McNally 1992; Moro 1997; Law 1999) that progressive existentials in fact involve a reduced relative clause (RRC). That is, all the material following the logical subject (the associate) is actually contained inside an RRC and is not part of the main clause (cf. (i)). If this is correct, we cannot use existentials to make any claims about VPE in main clauses. The supposed optional ellipsis of
} 
(31) a. Bob said there had been a clown dancing at his birthday party, but we all knew that there hadn't (been) a clown dancing....

b. Bob says there will be a clown dancing at his birthday party, but we all know that there won't (be) a clown dancing....

A\&H also note that there are certain idiomatic constructions which are dependent upon progressive aspect, for instance be dying to, meaning 'to be keen to'. Without progressive aspect, the idiomatic interpretation is altogether lost:

a. Bob is dying to meet you $=$ Bob is keen to meet you.

b. Bob has died to meet you $\neq$ Bob has been keen to meet you.

Once again, if we apply ellipsis to such idioms, and the idiomatic interpretation remains intact, this is indicative that progressive aspect is present in the underlying derivation. That is, there would be no potential mismatch interpretation available to mask the ellipsis of the progressive auxiliary. Here too, we see that the progressive auxiliary can indeed be elided:

progressive be would actually be optional ellipsis of copular be, and the supposed ellipsis of the entire phase observed in (21) and (22) would just be ellipsis of the nominal predicate.

(i) [TP There were [DP several hippos [RRC (who were) dancing]]]

However, although an RRC structure for existentials is possible, progressive existentials may also behave as matrix clause constructions, and moreover, so can those cases involving ellipsis. This is evidenced by the fact that these progressive existentials exhibit properties which relative clauses do not. For instance, Deal (2009) has observed that whilst reduced relatives must precede full relatives, no such restriction occurs on existentials:

(ii) a. The teacher scolded [the student [laughing in the hall] [who was wearing a cap]].

b. * The teacher scolded [the student [who was wearing a cap] [laughing in the hall]].

c. There is a man <laughing in the hall $>$ [who's wearing a cap] <laughing in the hall $>$.

Therefore, existentials have an underlying structure available to them that does not involve an RRC, but a matrix clause. Transferring this observation to existentials involving VPE, the same pattern holds:

(iii) Bob said there had been a man who was wearing a cap laughing in the hall, but in fact there hadn't (been) [a man who was wearing a cap laughing in the hall].

Furthermore, Chomsky (2001) has observed that existential constructions permit idiom chunks, whereas existential constructions containing a relative clause do not:

(iv) There was all hell breaking loose downstairs.

(v) * There was all hell which was breaking loose downstairs.

Once again, in conjunction with VPE, existentials behave according to the matrix clause structure:

(vi) Barney said there would be all hell breaking loose downstairs, but I didn't think there would (be) all hell breaking loose downstairs.

Finally, Milsark (1974); Rezac (2006) and Caponigro \& Schütze (2003) observed that existential constructions without a lexical verb, i.e., those in which only copular be is present, are illicit under an eventive interpretation:

(vii) *There's just been a dog.

Even in instances in which a relative clause is present, the derivation cannot be rescued since the lexical verb is contained inside the relative clause and therefore has no effect upon the acceptability of the main clause:

(viii) *There's just been a dog which was dancing on stage

Therefore, if existential constructions could only ever be formed from RRCs, and not from matrix clauses, then all existentials in English should be illicit under an eventive interpretation. That is, the lexical verb that we see in existentials is predicted to always be embedded inside an RRC and so should not be able to render the main clause as licit. This is not the case, however, since existentials with a progressive unergative verb are licit under eventive aspect:

(ix) There has just been a dog dancing on stage.

This suggests that progressive existentials have an underlying matrix clause structure available to them. Once again, in conjunction with VPE, existentials behave according to the matrix clause structure:

(x) Barney says there has just been a dog dancing on stage, but I don't think there has just been a dog dancing on stage.

All this implies that ellipsis in existential constructions is a normal case of main clause VPE and therefore that any conclusions drawn from these types of constructions can be drawn about VPE in general. 
(33) a. Bob has been dying to meet you, even though he says that he hasn't (been) dying to meet you.

b. Q: Are you sure Bob will be dying to meet George Lucas?

A: He most certainly will (be) dying to meet George Lucas.

If the progressive auxiliary is first merged in the progressive aspectual layer, this suggests that at least as much as the progressive aspectual layer can be included within the VP ellipsis site.

\subsubsection{Non-finite have}

A\&H observe that the issue of whether perfect have, merged in the perfect layer, is elidable, is still more complex. This is a notable grey area in ellipsis research with two competing viewpoints. Whilst Sag (1976), Zagona (1988), Lobeck (1987), Johnson (2001), Bošković (to appear a) Sailor (2009, 2012), Wurmbrand (2012) and Aelbrecht \& Harwood (2013) all take it that have can never be elided, Akmajian, Steele \& Wasow (1979) and Thoms (2011) have claimed that non-finite have can in fact be elided. Evidence cited in favour of the latter claim are sentences such as the following, in which have appears to be optionally elided:

John might have called, and Bill might (have) [ealled], too. (Wurmbrand 2012:(35))

Johnson (2001) and Wurmbrand (2012) argue, on the other hand, that the presence of perfect aspect in the first conjunct does not necessarily imply the presence of perfect aspect in the ellipsis site. In other words, they claim that when perfect have is apparently elided, the perfect layer, including the auxiliary, is in fact entirely absent from the second conjunct and that the elided phrase is instead understood simply as [eall]. This mismatch reading masks whether have can genuinely be elided. In order to rule out this mismatch interpretation Wurmbrand (2012) employs conflicting time specifications, forcing a reading in which perfect aspect is present in the underlying derivation. In such cases her informants judged ellipsis of have as ungrammatical. This suggests therefore that non-finite perfect have indeed cannot be elided.

$$
\text { John might have called yesterday, and Bill might *(have), two days ago. }
$$

(Wurmbrand 2012:(36))

Below I present three more contexts which can be exploited to ascertain whether or not non-finite perfect have can truly elide. The general finding is that have cannot so easily be elided, though I do not discount idiolectal or dialectal variation.

As discussed by $\mathrm{A} \& \mathrm{H}$, one means of testing whether have can be elided is to exploit certain fixed expressions which are dependent upon perfect aspect: have been to, and have been around the block. Without perfect aspect, these constructions are ungrammatical: ${ }^{28}$

$$
\text { a. Bob has been to Rome. }
$$

b. * Bob will be to Rome.

a. Bob has been around the block a few times.

b. * Bob might be around the block a few times.

If we apply ellipsis to such constructions, we can be certain as to the presence of perfect aspect in the underlying derivation. Therefore no aspectual mismatch interpretation would interfere to mask the potential ellipsis of have. In such cases, we see that the non-finite perfect auxiliary cannot in fact be elided:

\footnotetext{
${ }^{28}$ The construction in (36) was noted by A\&H. Thanks to Craig Sailor (p.c.) for pointing out the construction in (37) to me.
} 
(38) a. This time next year Bob will have been to Rome, and Betsy will *(have) been to Rome, too.

b. Betsy thinks that Bob might have been around the block a few times, and I also seem to think that he might $*$ (have) been around the block a few times.

A further test noted by A\&H exploits Lasnik's (1995b) and Warner's (1986) observation that, unlike lexical verbs, auxiliary verbs can only be elided if they have an identical antecedent: ${ }^{29}$

(39) a. Sue has been eaten by cannibals, and Bob might *(be) eaten..., too.

b. Sue might be eaten by cannibals now that Bob has *(been) eaten....

Thus, in (40) (from Thoms 2011), the passive auxiliary in the elided constituent must be identical to its antecedent form been, in order for the sentence to be grammatical:

Bob might have been fired, and Morag might have (been) fired, too.

This means that the elided passive auxiliary is dependent upon perfect aspect in order to be realised as been and fulfil the identity requirement. This provides us with another sentence that is reliant upon perfect aspect. No mismatch interpretation is available to mask the potential ellipsis of have. Once again, we find ellipsis of non-finite have to be unacceptable:

(41) Bob might have been fired, and Morag might *(have) been fired, too.

The results are similarly replicated with the copular auxiliary:

Bob might have been in the garden, and Morag might *(have) been in the garden, too.

Finally, Sailor (2012) notes that before-clauses also force a reading that is dependent upon perfect aspect, meaning that once again no mismatch interpretation is available to obscure the potential ellipsis of have. In such cases, Sailor's (2012) informants rejected ellipsis of have:

(43) Mary could have studied harder for the exam. Before finally taking it yesterday, she really should *(have).

(Sailor 2012:(36))

These four tests taken together suggest that non-finite perfect have generally cannot be elided.

However, the data is not quite so clear-cut as I have presented it here, as there tends to be disagreement with regards to the judgments. For instance, of the 20 British English speakers A\&H consulted, $20 \%$ actually accepted ellipsis of have in (38) ${ }^{30}$ All of their informants rejected ellipsis of have in sentences such as (41), though an anonymous reviewer accepts it, and this sentence has been reported as grammatical in Thoms (2011). Moreover, Wurmbrand (2012) has noted in her work a number of dissenting judgments in which ellipsis of have is deemed acceptable. Similarly, Sailor's (2012) work was based on American English informants, who he found to uniformly reject ellipsis of have, though he noted that a number of Canadian English speakers appeared to accept it. The issue as to whether have can be elided or not can therefore not be conclusively resolved at present. ${ }^{31}$

\footnotetext{
${ }^{29}$ Due to space restrictions I am unable to enter into an explanation for these facts and instead refer the reader to Lasnik (1995b) for the most standard account.

${ }^{30}$ The 20 speakers stem from all parts of the UK, though there is a concentration of speakers from the north of England and the midlands.

${ }^{31}$ An anonymous reviewer also presents the following potential counterexamples, which appear to show ellipsis of non-finite have:
} 
However, of the $20 \%$ of informants who accepted ellipsis of have in sentences such as (38), A\&H reported that some still regarded the sentence as degraded in comparison to when have has not been elided. This is a notable contrast with ellipsis of be and been, for which speakers notice no difference in acceptability between sentences in which be or been have been elided, and sentences in which they haven't. ${ }^{32}$ Moreover, it should be noted that no speaker consistently accepted ellipsis of have across the various tested phenomena. Again, this contrasts with ellipsis of be and been, in which all informants consistently accepted ellipsis of these auxiliaries. The fact also stands that there are many speakers who indeed outright reject ellipsis of have in all contexts. Given the general tendency of the data, I assume that the default option for English is that have cannot be elided. If the perfect auxiliary is merged in the perfect layer, then the fact that it cannot be elided suggests that the perfect layer is not included within the VPE ellipsis site.

However, I must also concede that there is idiolectal or dialectal variation in which certain speakers in certain contexts indeed allow for apparent ellipsis of have. Because deletion of have appears to be somewhat restricted and unstable in comparison to be/been deletion, I claim it must operate under a different, additional mechanism to be/been deletion. This additional mechanism I assume to only be available to certain speakers and in certain contexts, which would explain the restricted nature of apparent have-deletion. Because it is not yet predictable which speakers allow for ellipsis of have, nor in which contexts, it is difficult to ascertain exactly what this additional mechanism should be. Here I offer a few tentative proposals as to what operation may be involved in apparent have-deletion.

Modals aside, all finite auxiliaries in English have the property of being able to undergo cliticisation:

a. He's/They've gone home.

b. I'm/We're/He's going home.

Perfect have however, is unique in being the only non-finite auxiliary that can cliticise. This is perhaps best illustrated by the fact observed by Johnson (1988) and Kayne (1997) that have can cliticise to the modal and subsequently be pied-piped along with it during subject auxiliary inversion, whilst be cannot:

a. Shouldn't've Pam remembered her name?
b. * Shouldn't be Pam remembering her name?

As noted by Akmajian, Steele \& Wasow (1979) and Kayne (1997), non-finite have can cliticise in various forms, as either $-v e$, or the significantly reduced form of $-a:^{33}$

(i) Luke certainly could have won the race at that point, while Bill couldn't. But in the event, John then blew his chances by taking the wrong fork.

(ii) Hey, John might have aced that exam, and so might Bill. In which case, we will have a double celebration tonight.

(iii) By the time we get home tonight... wanna bet? ... John will have finished his homework, but Jane won't. However, of these three sentences, (iii) is the only real counterexample. Many informants judged the sentence in (i) acceptable under an ability reading in which the elided constituent could be read as "While Bill couldn't win the race at that point, in which perfect aspect is altogether absent from the clause. Under the counterfactual reading that the reviewer intended, many speakers had trouble accepting such sentences. The sentence in (ii) presents an instance of subject auxiliary inversion, a phenomenon which is not typical of standard VPE and has often been considered to comprise a different construction entirely. This leaves the counterexample in (iii) which, whilst accepted by some informers, is still considered degraded or unacceptable by others.

${ }^{32}$ Native speakers of English will hopefully notice that the sentence they have just read involved ellipsis of been and that there was no question as to the acceptability of this sentence.

${ }^{33}$ See Kayne (1997) for arguments in favour of an analysis in which these forms actually constitute a separate form from the perfect auxiliary, namely the complementiser of. 
a. You should've closed the door behind you.

b. You shoulda closed the door behind you.

Have in fact appears to be particularly susceptible to ever more extreme forms of cliticisation in which its phonological form may be reduced to the point at which it is not pronounced at all. The contexts in which such a phenomenon can occur are rare, but one such instance is in wh-questions in Northern varieties of British English:

\section{a. $\%$ Where you been? \\ b.\% What you done?}

I conjecture that another context in which such extreme cliticisation applies, albeit not necessarily restricted to Northern varieties of British English, is under ellipsis. That is, the apparent ellipsis of non-finite have could in fact be attributed to extreme cliticisation of have to the point of non-pronunciation, adjacent to an ellipsis site. ${ }^{34}$

Alternatively, Kayne (1997:49) has claimed that "some [varieties of] English are able to embed participial phrases directly under modals, without the intermediary of an auxiliary verb have." This is directly observable in other Germanic languages such as the closely related language of Swedish, as well as Norwegian (Taraldson 1984), Icelandic and Faroese (Einarsson 1945; Lockwood 1977). I illustrate this here with Norwegian:

$$
\begin{aligned}
& \text { Vi skulle gjort det før } \\
& \text { we should done it before } \\
& \text { 'We should have done it before' }
\end{aligned}
$$

It therefore may be possible that what looks like ellipsis of non-finite have in the English of some speakers may in fact be an instance of the modal introducing perfect aspect without the intervening auxiliary verb have. This particular phenomenon may have died out in certain varieties of English, but may exist in others in the context of ellipsis.

To conclude this discussion, I claim that the default option in English is that non-finite have cannot be elided and that those speakers who do allow for such apparent ellipsis utilise a different mechanism to obtain this effect, but which is not actually ellipsis in itself. I have presented two such potential mechanisms above, though I leave thorough investigation of these proposals open to further research. ${ }^{35}$

\subsubsection{Taking stock: VP elides as much as $v P_{\text {prog }}$}

I have so far shown, following A\&H, that progressive, passive and copula auxiliaries can be elided under English VPE, whilst, under the default option, perfect have cannot. It is standardly assumed that in order for such auxiliaries to be elided they must have been merged within the ellipsis site. Since the auxiliaries which can uncontroversially elide are all merged

\footnotetext{
${ }^{34}$ It is well-known that cliticisation of finite auxiliaries adjacent to an ellipsis site leads to ungrammaticality. However, Wood (1979) and Kayne (1997) have noted that it is perfectly acceptable for non-finite have to cliticise adjacent to an ellipsis site:

(i) A: Don't you think that Roland Rat should've left the party by now?

B: Yeah, he really should've/shoulda.

${ }^{35}$ An anonymous reviewer suggests that the clause internal phase, which in the next section I will argue to be as large as progressive aspect (but no larger), could act as a constraint on the amount of structure that could be minimally elided, but that ellipsis could also optionally target structures larger than this. In principle I am not opposed to this proposal, but in the following sections I show that VP fronting, idiomatic constructions and existential constructions uniformly privilege the same unit of structure, that is, the progressive aspectual layer and not the perfect layer. It would therefore be a mystery why VPE can optionally privilege domains of structure larger than this, but the other phenomena cannot.
} 
within or below the progressive aspectual layer, this suggests that the ellipsis site can be as large as the progressive aspectual layer, but no larger:

$$
\text { [TP [ModP }[\text { InfP }[\mathrm{vPperf} \text { have }[\operatorname{PerfP} \text { ([vprog be }[\operatorname{ProgP}[\mathrm{vP} \text { be }[\text { VoiceP }[\mathrm{VP}]]]]]]]]]
$$

As said above, this explains why being is always elided: it only raises to ProgP, which is inside the ellipsis site. Being never raises out of the ellipsis site, so it never escapes ellipsis:

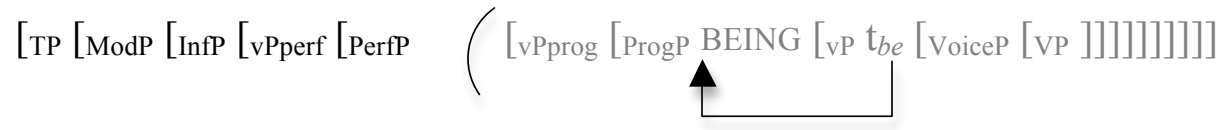

Note that, since I assume WYSIWYG with respect to which projections are present in the structure, I predict that in the absence of progressive aspect, the site of English VPE is vP:

$$
\text { [TP }[\operatorname{ModP}[\operatorname{InfP}[\mathrm{vPperf}[\operatorname{PerfP} \quad(\quad[\mathrm{vp} \text { be }[\text { voiceP }[\mathrm{vP}]]]]]]]]]]
$$

To finish this section, I briefly illustrate how I take the optional ellipsis of be and been to be derived. Here I appeal to A\&H's analysis.

Recall first of all from section 2.2 that I take the overt raising of auxiliaries to be for PF reasons. That is, the features they check must be checked before spell out at PF rather than at LF otherwise a PF violation would ensue. Under this assumption, A\&H claim that the optional deletion of progressive, passive and copula be/been is derived via optional raising of these auxiliaries out of the $\mathrm{vP}_{\text {prog }} / \mathrm{vP}$ ellipsis site to the heads of PerfP and InfP, crucially outside of the ellipsis site, in order to check their inflectional features. If the auxiliary raises and checks its feature, it survives ellipsis. If it fails to raise, it remains inside of the ellipsis site and is elided. Of course, this means that the auxiliary has failed to check its inflectional features before PF, which should cause the derivation to crash. However, ellipsis, being a PF deletion operation, is able to rescue the derivation. The problematic auxiliary, along with its unchecked feature, is deleted at PF by ellipsis, and is therefore no longer a problem for the derivation. The diagrams in (52) show how ellipsis and non-ellipsis of non-finite auxiliaries works with the progressive auxiliary. This proposal sits in line with a large body of work that claims that ellipsis can act as a PF rescue operation for various phenomena (see Ross 1969; Chomsky 1972; Chomsky \& Lasnik 1993; Lasnik 1995a, 1999, 2001a,b; Merchant 2001; Fox \& Pesetsky 2003; Bošković 2011; Müller 2011).

Non-deletion of be/been

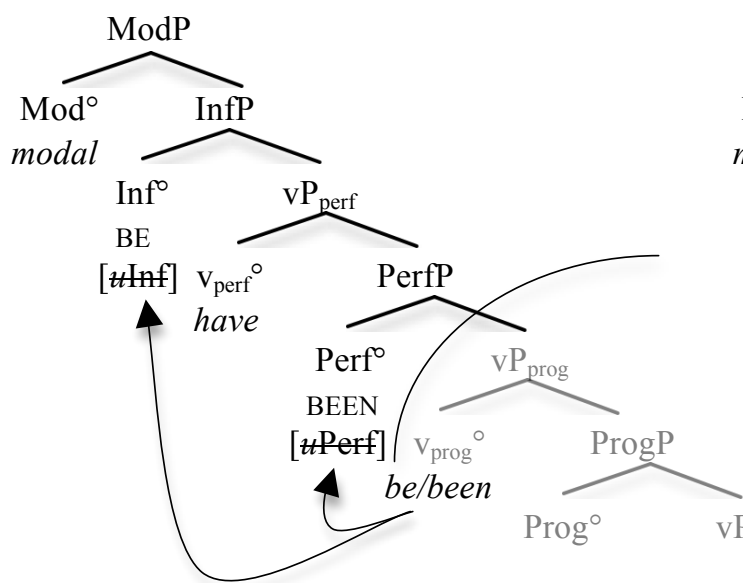

Deletion of be/been

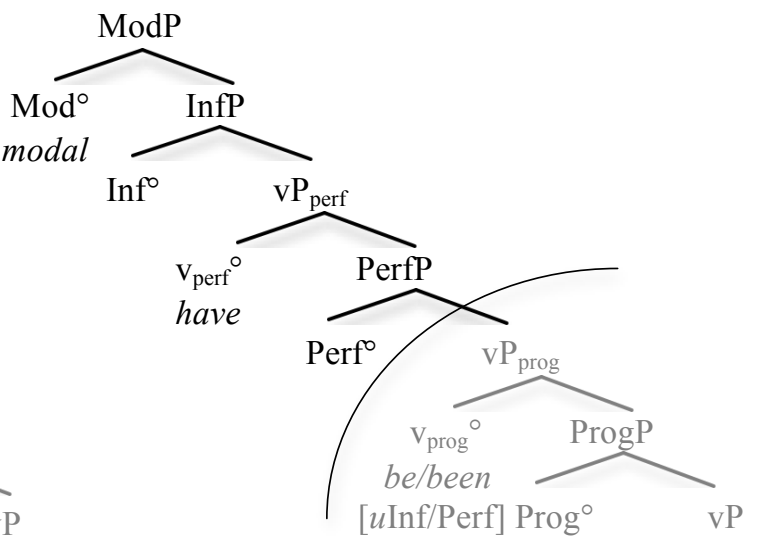

Having established that VPE in English targets as much as the progressive layer when such projections are present, the following sub-section returns to the discussion of how ellipsis can 
be reconciled with phase theory. I show how the conclusions just drawn indicate that progressive aspect, when it projects, is contained within the clause internal phase in English.

\subsection{VPE and phases}

VPE in English has been analysed by Gengel (2007, 2008), Rouveret (2012), Sailor (2012), Wurmbrand (2012) and Bošković (to appear a) as privileging that part of the clause internal phase that is sent to spell out. Given the conclusion drawn in section 3.2, namely that VPE targets as much as the progressive aspectual layer (but not the perfect aspectual layer), this implies that the progressive layer should be contained within the clause internal phase in English. Therefore, the clause internal phase can be larger than vP as was traditionally assumed.

Section 3.1, however, established that ellipsis may target either the phasal complement, or the phase itself. So whilst we have determined that the progressive layer is contained within the clause internal phase, it is not yet clear whether the progressive layer comprises the phasal complement, or whether one of the progressive projections in fact projects the clause internal phase itself. This section discusses the exact identity of the clause internal phase.

In section 3.1 it was generally shown that if high movement, that is, movement into the left periphery, could take place out of an ellipsis site, this was an indication of ellipsis privileging the phasal complement. Moreover, it was noted that VPE permits, for the most part, such extraction (see Baltin 2012), except in exceptional circumstances such as in existential constructions. This suggests that VPE mostly targets the phasal complement rather than the entire phase, apart from a few rare instances. I will generally take this to be the case.

I claim that when the progressive aspectual layer is present, the head of $\mathrm{vP}_{\text {prog }}$ itself, $\mathrm{v}_{\text {prog }}{ }^{\circ}$ (in which progressive $b e$ is base generated), acts as the clause internal phase head. ${ }^{36}$

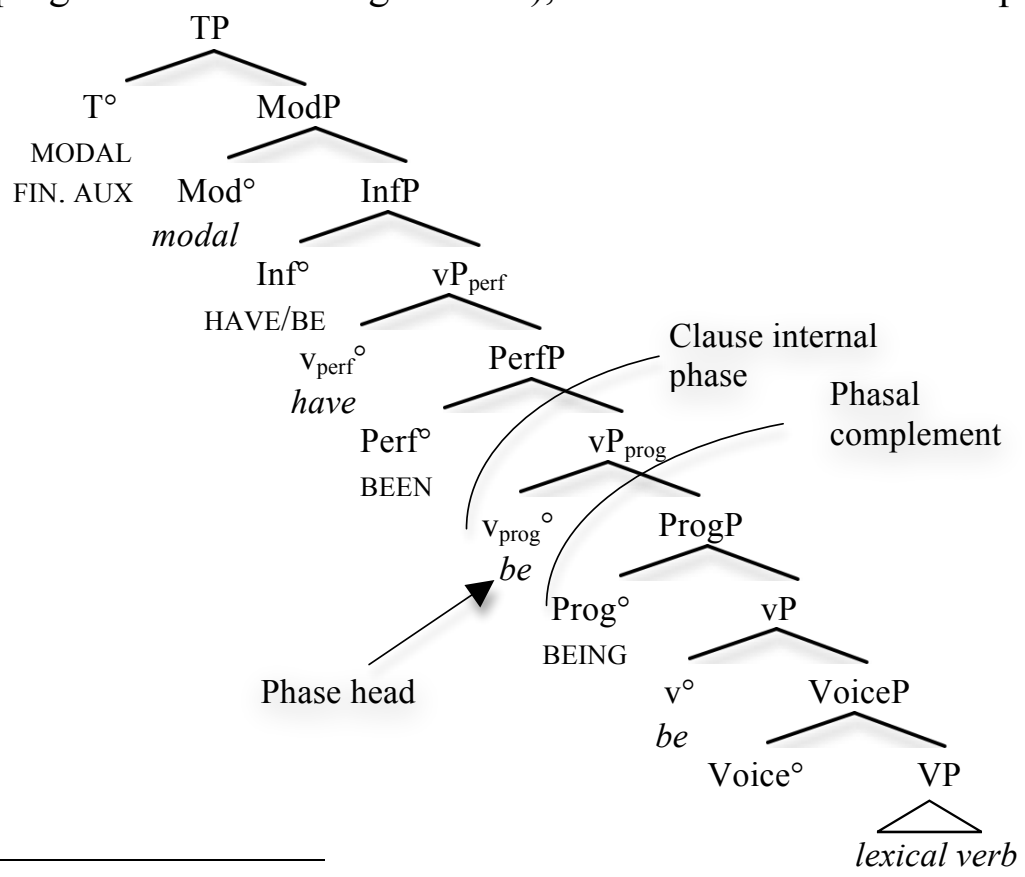

${ }^{36}$ An alternative would be to claim that Perf $^{\circ}$, when it projects, acts as the clause internal phase head, with the progressive aspectual layer its phasal complement. This would allow the progressive aspectual layer to be consistently included within the ellipsis site. Indeed, Bošković (to appear a) has claimed exactly this. See section 6.3 for a critical analysis of this approach.

Another potential option is to instead claim that $\mathrm{v}_{\text {perf }}{ }^{\circ}$, headed by have, acts as the clause internal phase head. In section 3.2 I established that the default option for English is that have cannot be elided, but this only indicates that $\mathrm{vP}_{\text {perf }}$ should not be included within the ellipsis. It makes no claims about PerfP itself. However, this would entail that as much as PerfP consistently sits within the phasal complement, meaning PerfP should be uniformly targeted by VPE. Since I claim been only raises as far as Perf ${ }^{\circ}$, this would incorrectly predict that been is obligatorily elided under English VPE rather than optionally. Moreover, as will be illustrated in sections 4, 5 and 7, there is no evidence that the perfect aspectual layer constitutes part of the clause internal phase. For these reasons, I reject this analysis also. 
This implies that ProgP is consistently within the phasal complement, so it is uniformly targeted by English VPE, accounting for the obligatory ellipsis of being and the lexical verb.

Of course, I claimed in section 3.2 that VPE targeted $\mathrm{vP}_{\text {prog }}$ so as to capture the optional ellipsis of the progressive auxiliary. To remain consistent with this, I claim that optional auxiliary ellipsis is one of the rare cases in which VPE targets the entire phase rather than just the phasal complement so as to include the non-raised auxiliary within the ellipsis site. That is, if the progressive auxiliary be/been has not risen out of $\mathrm{v}_{\mathrm{prog}}{ }^{\circ}$ to $\mathrm{Perf}^{\circ}$ or $\mathrm{Inf}^{\circ}$, and therefore still bears an uninterpretable feature, ellipsis privileges the entire phase. This deletes the auxiliary along with its unchecked feature, thereby rescuing the derivation. So the optional deletion of be and been is in fact an interplay between optional raising of the auxiliary, and optionally eliding the entire phase rather than just the phasal complement. Below I illustrate the four paths available to the derivation, and explain what happens in each case:

A) The auxiliary raises and ellipsis targets the phasal complement:

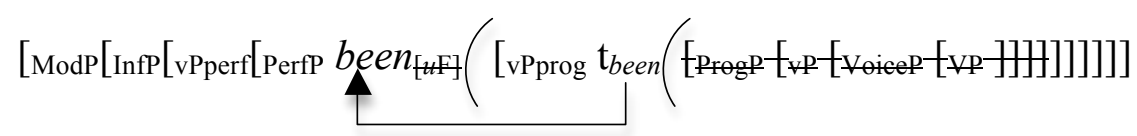

Result: the auxiliary checks its feature and survives ellipsis - the derivation is accepted.

B) The auxiliary raises and ellipsis targets the entire phase:

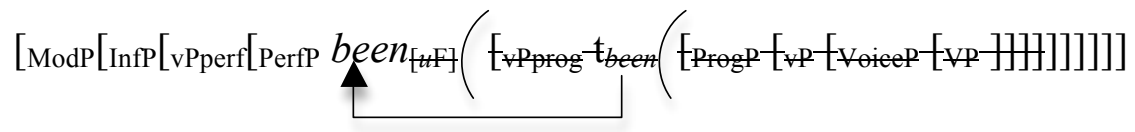

Result: the auxiliary checks its feature and survives ellipsis - the derivation is accepted. In principle this derivation is possible. However, I claim that ellipsis of the entire phase occurs in these sorts of contexts only as a means of rescuing the derivation, i.e. deleting a non-raised auxiliary and its offending unchecked feature. Because in this instance there is no offending auxiliary to delete, ellipsis does not need to privilege the entire phase. Therefore A) is chosen over B), in which case only the phasal complement is elided.

C) The auxiliary does not raise and ellipsis targets the phasal complement:

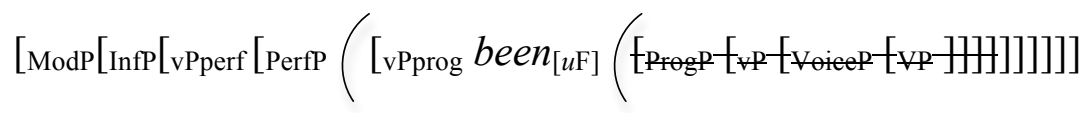

Result: The auxiliary survives ellipsis but the derivation crashes due to the presence of the unchecked feature on the auxiliary.

D) The auxiliary does not raise and ellipsis targets the entire phase:

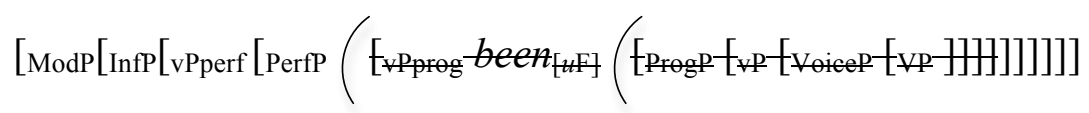

Result: the auxiliary and its unchecked feature are deleted; the derivation is rescued.

This proposal for optional auxiliary ellipsis is in the spirit of Bošković (to appear a), who also assumes that when the auxiliaries be or been have been optionally elided, VPE targets the entire phase instead of the phasal complement. ${ }^{37}$ In favour of this claim, Bošković (to appear

\footnotetext{
${ }^{37}$ The difference between Bošković's (to appear a) approach and the one I advocate here is that Bošković (to appear a) assumes optional auxiliary ellipsis to only be due to a choice between eliding the phasal complement or the entire phase, whereas I assume optional auxiliary raising to also play a role. As will be illustrated in
} 
a) notes that high movement is severely degraded when be or been have been elided, whereas similar A'-extraction is far more acceptable when be or been are stranded by ellipsis:

a.?* You wonder by whom Betsy must have been being hassled, and I wonder by whom Jane must have.

b. ? You wonder by whom Betsy must have been being hassled, and I wonder by whom Jane must have been.

(Bošković to appear a:(85) and (86))

This suggests that generally VPE targets the phasal complement, except in those instances in which be or been haven't raised, when VPE targets the entire phase to rescue the derivation.

In section 3.2 I also concluded that in the absence of progressive aspect, VPE targets vP. If this is correct it implies that the size of the clause internal phase can vary depending on which projections are present in the structure. In the remainder of this section I briefly discuss what I take to be the identity of the clause internal phase in the absence of progressive aspect.

Given the structure in (59), I take $v^{\circ}$ to act as the clause internal phase head in the absence of progressive aspect.

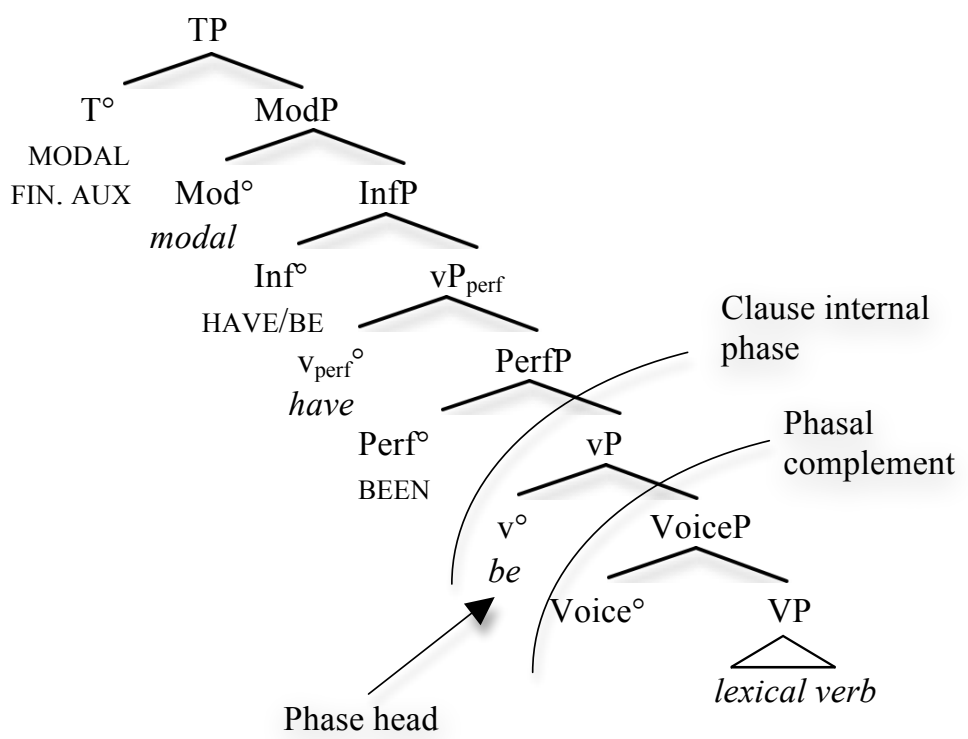

This implies that VoiceP is the phasal complement and so is consistently targeted by VPE, whilst $\mathrm{vP}$, the clause internal phase itself, may be optionally included within the ellipsis site. I follow Bowers (2002) in assuming that the lexical verb raises consistently to Voice ${ }^{\circ}$, but does not necessarily raise further than this. Therefore the lexical verb never raises out of the phasal complement and so is uniformly elided under VPE. With regards to the optional ellipsis of passive and copular be and been, I assume something similar to the optional deletion of the progressive auxiliary, namely an interplay between optional auxiliary raising and VPE optionally privileging the entire phase rather than just the phasal complement. That is, standardly the auxiliaries be and been raise out of $\mathrm{v}^{\circ}$ to either Perf ${ }^{\circ}$ or $\operatorname{Inf}^{\circ}$ in order to have their inflectional features checked. Generally in such instances, VPE targets the phasal complement of Voice $^{\circ}$. However, if these auxiliaries do not raise and remain in $\mathrm{v}^{\circ}, \mathrm{VPE}$ privileges the entire clause internal phase of $\mathrm{vP}$ so that the non-raised auxiliary is included in the ellipsis site and is therefore deleted along with its problematic inflectional feature, thereby rescuing the derivation. Again, evidence in favour of this type of analysis is the fact that, as noted by Bošković (to appear a), high movement is severely degraded when the passive auxiliary has been elided, suggesting the entire phase is privileged in such instances, whereas

section 4, this optional raising of auxiliaries in ellipsis contexts is crucial in accounting for the VP fronting data, something which Bošković's (to appear a) account is unable to straightforwardly explain. See section 6.3 for a detailed discussion of Bošković's (to appear a) analysis. 
similar extraction is much more readily accepted when the passive auxiliary has been stranded, suggesting that only the phasal complement is targeted then:

(60) a.?* You wonder on which table your book must have been put, and I wonder on which table my CD must have.

b. ? You wonder on which table your book must have been put, and I wonder on which table my CD must have been.

(Bošković to appear a:(85) and (86))

To summarise, I have argued in this section that in the presence of progressive aspect, $\mathrm{vP}_{\text {prog }}$ acts as the clause internal phase. Generally, VPE privileges the phasal complement of ProgP, explaining the uniform ellipsis of being and the lexical verb. When the progressive auxiliary be or been does not raise out of $\mathrm{V}_{\mathrm{prog}}{ }^{\circ}$, however, VPE privileges the entire phase, deleting the progressive auxiliary. In the absence of progressive aspect, on the other hand, $\mathrm{vP}$ acts as the clause internal phase. VPE then elides the phasal complement of VoiceP, which contains the lexical verb and its internal arguments. But when the passive or copular non-finite auxiliary does not raise out of $\mathrm{v}^{\circ}$, VPE deletes the entire phase, including the offending auxiliary. This set of claims also implies that the perfect aspectual layer does not constitute part of the clause internal phase.

If this line of reasoning is correct, it suggests that the clause internal phase can vary in size, with $\mathrm{vP}_{\text {prog }}$ acting as the phase when the progressive aspectual layer is present, and $\mathrm{vP}$ otherwise. In section 6 I propose a formal explanation of how such a variable phase boundary can be made possible under phase theory.

In the following section I discuss certain VP fronting phenomena which suggest, in accordance with Fowlie's (2010) and Roberts' (2010) claims that only phases can undergo movement, that the progressive aspectual layer is included within the clause internal phase.

\section{Fronting Phenomena and Phases}

Akmajian \& Wasow (1975), Zagona (1982) and Johnson (2001) have noted there is a relation between VPE and VP fronting (VPF) in that what is elided by VPE, is also fronted under VPF. That is, being is obligatorily fronted along with the lexical verb under VPF:

(61) If Darth Vader says that Han Solo was being frozen in carbonite, then...

a. [being frozen in carbonite] he was.

b. * [frozen in carbonite] he was being.

(62) If Darth Vader says that Han Solo was being stubborn, then...

a. [being stubborn] he was.

b. $*$ [stubborn] he was being.

Again, akin to VPE, non-finite have cannot be fronted:

(63) If Luke says he would have fought hard, then...

a. [fought hard] he would have.

b. * [have fought hard] he would.

A parallel case is that of specificational psuedo-clefting, which has also been argued to involve fronting (Blom \& Daalder 1977; Declerck 1988; Den Dikken 1995; Heggie 1988; Heycock 1994; Higgins 1979; Moro 1997 and Verheugd 1990 (cited in Den Dikken 2006)). Sailor (2012) has noted that such instances of fronting also seem to target the same material. That is, being must be fronted with the lexical verb when pseudo-clefting occurs, whilst nonfinite have cannot be: 
(64) Elmer Fudd should be being criticised.

a. No, [being praised] is what Elmer Fudd should be.

b. * No, [praised] is what Elmer Fudd should be being.

(65) Elmer Fudd should have been criticised.

a. No, [praised] is what Elmer Fudd should have been.

b. * No, [have been praised] is what Elmer Fudd should.

Thirdly, Emonds (1976), Haegeman (2008), Heycock \& Kroch (1999) and Hooper \& Thompson (1973) have also analysed predicate inversion contexts as involving fronting of the predicate. In such cases, being is obligatorily fronted, whilst have cannot be:

(66) a. [Also being examined for body parts] is the tonnes of rubble being removed from the site. $\quad$ (Guardian, 14.9.1, p4, col 6, cited in Haegeman 2008:(19))

b. * [Also examined for body parts] is being the tonnes of rubble being removed from the site.

(67) a. [Also examined for body parts] will have been the tonnes of rubble being removed from the site.

b. * [Also have been examined for body parts] will the tonnes of rubble being removed from the site.

If being has risen to occupy $\operatorname{Prog}^{\circ}$ in the progressive aspectual layer of the clause, yet does not escape fronting, this suggests that as much as the progressive aspectual layer is fronted under fronting phenomena. If non-finite have raises to occupy $\operatorname{Inf}^{\circ}$ and cannot be fronted, this suggests that the modal layer at least is not included in the fronted constituent.

Interestingly, Akmajian, Steele \& Wasow (1979) and Roberts (1998) note that, contrary to VPE, be and been cannot be fronted under VPF, not even optionally. Sailor (2012) notes the same for pseudo-clefting, and Aelbrecht \& Harwood (2013) for predicate inversion:

(68) If Darth Vader says Han Solo has been frozen in carbonite, then...

a. [frozen in carbonite] he has been.

b. * [been frozen in carbonite] he has.

(69) If Darth Vader says Han Solo will be frozen in carbonite, then...

a. [frozen in carbonite] he will be.

b. * [be frozen in carbonite] he will.

(70) Elmer Fudd should have been praised.

a. No, [criticised] is what Elmer Fudd should have been.

b. * No, [been criticised] is what Elmer Fudd should have.

(71) Elmer Fudd should be praised.

a. No, [criticised] is what Elmer Fudd should be.

b. * No, [be criticised] is what Elmer Fudd should.

(72) a. [Also examined for body parts] has been the tonnes of rubble being removed from the site.

b. * [Also been examined for body parts] has the tonnes of rubble being removed from the site. 
(73) a. [Also examined for body parts] will be the tonnes of rubble being removed from the site.

b. * [Also be examined for body parts] will the tonnes of rubble being removed from the site.

If $b e$ raises to $\mathrm{Inf}^{\circ}$, and cannot be fronted, this once again suggests that the modal layer cannot be included in the fronted constituent. More importantly, however, if been raises to Perf ${ }^{\circ}$, and also cannot be fronted, this suggests that the perfect aspectual layer also cannot be included in the fronted constituent. Therefore the fronted constituent is as large as the progressive aspectual layer, but no larger.

Note that the fact that be and been cannot be optionally fronted, in contrast to the optional ellipsis data, can easily be accounted for under the system of Aelbrecht \& Harwood (2013) that has been adopted in this paper: the optional ellipsis of such auxiliaries was made possible by be and been failing to raise, thereby remaining within the ellipsis site and having their unchecked inflectional features deleted at PF by ellipsis, thereby rescuing the derivation. In fronting phenomena on the other hand, no ellipsis occurs to rescue the derivation. For be or been to undergo fronting they would have to fail to raise out of the fronted constituent, leaving their inflectional features unchecked. But because no ellipsis occurs, the unchecked features remain in the structure, causing the derivation to crash at PF.

Up to this point I have argued that as much as the progressive aspectual layer is included within the fronted constituent in various VP fronting phenomena, akin to VPE. But the question now is: what does this have to do with phases? Holmberg (2001), Chomsky (2005), Roberts (2010) and Fowlie (2010) have all claimed that the only phrases that can undergo movement are phases. This has been further assumed by Aelbrecht \& Den Dikken (to appear) and Koopman (2010) in the context of prepositional phrases. Here I briefly outline the general empirical advantage to this claim. The phrasal constituents that can typically move in a sentence are commonly taken to be DPs, PPs, AdjPs, AdvPs, vPs and CPs. All of these elements have been claimed by various authors to act as phases (Aelbrecht \& Den Dikken to appear; Bošković to appear a, b; Chomsky 2000, 2001, 2005; Fowlie 2010; Koopman 2010). ${ }^{38}$ It has long been known, however, that phasal complements, such as TP, cannot move independently (Abels 2003). This has often been attributed to the fact that such constituents would have to proceed via the specifier of the phase edge. However, such complementiser to specifier movement within the same phrase is deemed an anti-locality violation, hence the reason why movement of the phasal complement is impossible. An alternative means of looking at this is simply that the complement of a phase head can never be a phase, and therefore cannot undergo movement, as suggested by Chomsky (2005).

Therefore, if only phases can undergo movement, this would suggest that the VPF-type phenomena already discussed are instances of the clause internal phase undergoing movement to the left periphery. Since I have shown that progressive aspect, yet no higher material, is included within the fronted constituent, this suggests that the progressive aspectual layer acts as the clause internal phase when it is present in the derivation. Similarly it suggests that higher aspectual forms such as perfect aspect are not included within this lower phase. Since I assume WYSIWYG, I propose that in the absence of the progressive aspectual layer, the vP constituent is fronted, suggesting that $\mathrm{vP}$ acts as the phase in the absence of progressive aspect.

Up until now, the strongest evidence for the progressive aspectual layer constituting part of the clause internal phase is the fact that being is obligatorily elided and fronted under VPE and VPF phenomena. Of course, as mentioned in section 3.2, an alternative analysis is that being is the only auxiliary which does not raise out of $\mathrm{v}^{\circ}$ (Lobeck 1987; Bošković 2004, to

\footnotetext{
${ }^{38}$ Of course, more work needs to be done on this area to explain how stranding of PPs and quantifiers is able to occur, and potentially roll-up movement also. These issues however are beyond the scope of this paper.
} 
appear a; Thoms 2011; Sailor 2012). Despite being something of a stipulation, the advantage this analysis affords us is that we are able to maintain the notion that VPE and VPF consistently target the $\mathrm{vP}$ domain, rather than having to posit some kind of variable phase boundary as I have been arguing for in this paper. In section 3.2 I attempted to dispel the nonraising of being account, but these arguments aside, the analysis remains so far a genuine alternative to the one proposed in this paper.

In the next section, however, I show how Svenonius' (2005) claim that idiomatic constructions should be constrained by phases predicts that the progressive aspectual layer should be included within the clause internal phase to the exclusion of higher aspectual forms. This abstracts away from auxiliaries and shows that progressive aspect in general shares properties with the lexical verb and its arguments that higher aspectual forms do not. This suggests therefore that the unique behaviour of being which we have so far observed, is not attributable to a unique property of this auxiliary in particular, but a unique property of progressive aspect in general, namely that it constitutes a part of the clause internal phase whilst higher aspectual forms do not.

\section{Idiomatic Constructions and Phases}

A question puzzling syntacticians and semanticists is exactly how we are able to deduce the idiomatic interpretation of an idiom when it can in no way be derived from the meanings of any of the individual lexical items that comprise it.

Jackendoff (1997) accounts for this puzzle by claiming that, as well as individual lexical items being listed in the lexicon, so are actual chunks of syntactic structure. For instance, as well as 'kick', 'the' and 'bucket' being individually listed in the lexicon, so too is the following syntactic structure:

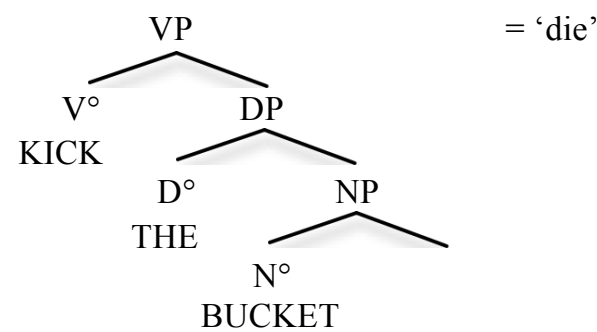

Whenever this specific structure shows up in the derivation, our lexicon instantly recognises it as (potentially) corresponding to the meaning 'die'.

Further to this, Chomsky $(1980,1981)$ and Marantz (1984) have noted a certain regularity to idiomatic expressions, in that they often correspond to verb phrases, such as 'kick the bucket', 'spill the beans', 'call the shots', 'bring down the house'. There are also a number of idioms which go beyond the initial verb phrase and incorporate the subject as well, i.e., 'heads will roll', 'the shit hit the fan', or 'the cat is out of the bag', suggesting that idioms potentially correspond to as much as vP. In this sense, idioms seem to correspond to syntactic constituents.

Svenonius (2005) has noticed that there seems to be a strict separation between the vP and TP domains with regards to idioms. Whilst verbs regularly form idioms with their arguments and other material contained within $\mathrm{vP}$, they do not form idioms with material generated outside of it. That is, idioms seem not to exist in which a particular tense, modality or aspect contribute to the idiom. Whilst material in the TP domain can obviously be used in conjunction with idioms, as in (75) for instance, the particular idiomatic interpretation is not dependent upon these items. As (76) illustrates, the idiomatic expression is maintained if the material from the TP domain is changed:

$$
\text { He might kick the bucket }=\text { He might die. }
$$


a. He kicked the bucket $=$ He died.

b. He has kicked the bucket $=$ He has died.

c. Did he kick the bucket? = Did he die?

This contrasts with the material from the vP domain upon which the idiom is dependent. If material from this lower domain is altered, the idiom is lost:

(77) a. He hit the bucket $\neq$ He died.

b. He kicked the tub $\neq$ He died.

c. He kicked a bucket $\neq$ He died.

This has led Svenonius to state that there is a size limitation to idioms, namely that of vP. Whilst idioms may indeed be smaller than this boundary, they can be no larger than it. He claims that this limit corresponds to that of a phase. This makes intuitive sense: if phases are shipped off from the syntax and interpreted separately from one another, there is no way in which a particular syntactic structure can be idiomatically interpreted by the lexicon if there is still material left behind in the syntax in the higher phase upon which the idiom is reliant. Svenonius therefore concludes that idioms are constrained by phases in that, whilst they can be smaller than the phasal domain, they can definitely be no larger than it. So essentially, idioms are unable to straddle the phase boundary. ${ }^{39}$

One problem that Svenonius notes with this analysis, however, is the fact that there are a number of idioms which are reliant upon progressive aspect. Consider for instance the idiom that we previously encountered in section 3.2 :

$$
\mathrm{XP}_{\text {subj }} \text { be dying to VP (e.g. Bob is dying to meet you.) }
$$

Most native speakers of English recognise this string as corresponding to the idiomatic interpretation ' $\mathrm{X}$ is keen to do something'. Recall however, what happens when we lose the progressive aspect from the idiom:

$$
\text { Bob has died to meet you } \neq \text { Bob has been keen to meet you. }
$$

In the absence of progressive aspect, we lose the idiomatic interpretation, and are only left with the rather obscure literal meaning. This is a clear instance of an idiom which relies upon progressive aspect for its interpretation. Under a more traditional approach to phases in which only vP constitutes the clause internal phasal domain, this is a definite violation of Svenonius' claim that idioms may not straddle the phase boundary. However, given the arguments put forward so far in this paper, it acts as further evidence in support of the idea that the progressive aspectual layer constitutes a part of the clause internal phase.

The idiom in (78) is not the sole counterexample to Svenonius' (2005) claims either. There are a number of such idioms that are dependent upon progressive aspect: ${ }^{40}$

\footnotetext{
${ }^{39}$ Interestingly it has been noted that idioms can be comprised of both the vP and CP phasal domains collectively:

(i) a. Is the Pope Catholic?

b. Do bears shit in the woods?

But these idioms are notably different in not being productive. They are closed-off constructions that cannot be incorporated into a normal sentence since nothing about them is adaptable, not even their clause type (the hash marker indicates loss of the idiomatic meaning):

(ii) a. \# The Pope is Catholic.

b. \# Bears shit in the woods.

${ }^{40}$ Svenonius (2005) notes the idiomatic construction in (80)a. Thanks to Craig Sailor (p.c.) for making me aware of the idiomatic constructions in (80)b and (80)c.
} 
(80) a. Something is eating Bob = Something is bothering Bob.

b. Bob is pushing up daisies $=$ Bob is dead.

c. You are cruising for a bruising $=$ You are heading for trouble.

d. They were chomping at the bit $=$ They were keen to get started.

Furthermore, there appear to be no verbal idiomatic constructions dependent upon perfect aspect or any other higher material. ${ }^{41}$ Given Svenonius' claim that idioms are constrained by phasal domains, this suggests that progressive aspect is contained within the clause internal phase, whilst perfect aspect is not. This illustrates a unique property of progressive aspect independent from auxiliaries. This suggests that the peculiar behaviour of being observed so far in sections 3 and 4 is not derived via any unique properties of being itself, but is instead a general property of progressive aspect, namely, progressive aspect constitutes part of the clause internal phase at the exclusion of higher aspectual forms.

In the next section I demonstrate how we can formalise the claim that the progressive aspectual layer acts as the clause internal phase when present in the derivation, and that vP does when the progressive layer is absent.

\section{Formalising the Variable Phase Boundary}

Here I provide a formal explanation for how a variable phase boundary, of the sort I have argued for, is possible within the Minimalist framework. Section 6.1 provides the formal analysis itself, 6.2 tries to provide a deeper understanding of the aspectual divide in terms of predication, whilst 6.3 places the analysis within the general move towards a more dynamic understanding of phases, and briefly discusses some of the prior literature on this topic.

\subsection{The variable phase boundary}

Essentially I propose that we should maintain the notion of phases being determined by subnumerations (Chomsky 2000, 2001). As discussed in section 2, the main clausal spine is

41 Two apparent counterexamples, which we already encountered in section 3.2, exist to this claim. As previously noted, the following two constructions are dependent upon perfect aspect:

(i) John has been to Rome.

(ii) John has been around the block a few times.

Whilst I do not have a definite explanation for these counterexamples, it is possible that these constructions are not idioms in the same sense that the progressive idioms are. It should be noted that other than perfect aspect, a common element across these two sentences is that neither contain a lexical verb, and instead employ the auxiliary been. It is possible that this auxiliary is an independent lexical item that carries with it some meaning of transit. This is evidenced by the fact that the same auxiliary can be used to similar effect in the closely related language of Dutch:

(iii) Ik ben naar de kapper

I am to the hairdressers

'I am going to the hairdressers.'

Of course, the fact that the Dutch instance of this auxiliary is not dependent upon perfect aspect but the English equivalent is remains to be explained. One possibility is that this particular auxiliary is always listed in the English lexicon as been, but is listed more abstractly in the Dutch lexicon.

It should also be noted that most idioms may lose their idiomatic interpretation if you alter the material upon which they are reliant, but the result is still a grammatical sentence. When perfect aspect is removed from the sentences in (i) and (ii) on the other hand, the resulting sentence is entirely ungrammatical, suggesting that these types of constructions are not in fact idioms:

(iv) * John is to Rome.

(v) * John might be around the block a few times.

Another idiom which is sometimes raised as a possible counterexample is the saying 'The cat has got your tongue', meaning You seem speechless, which at first glance appears to be dependent upon perfect aspect. However, the following two sentences demonstrate that the idiom can be maintained in the absence of perfect aspect:

(vi) The cat has your tongue $=$ You are speechless.

(vii) The cat got his tongue $=$ He was speechless. 
divided into two sub-numerations, one containing the lexical verb and all related projections, and the second containing tense and the various heads that potentially make up Rizzi's (1997) CP layer (though I will collectively refer to them as C). Each of these sub-numerations acts as a phase when it has been merged into the syntactic workspace. Under the original formulation of phases it was assumed that once $\mathrm{v}$ was merged into the workspace, the first phase was complete, and upon merger of $\mathrm{C}$ the second phase was complete. However, determining the completion of a phase upon the merger of a particular head seems to be rather stipulatory, and a needless complication to the system. Moreover, it is often claimed that such heads are not always present in the structure, yet evidence suggests that the phase remains intact. Specifically $\mathrm{v}^{\circ}$ has been taken to be absent with unaccusative verbs (Hale \& Keyser 1993). Legate (2003) has shown, however, that a clause internal phase still seems to be projected in the structure even with an unaccusative verb.

There is a way of solving these issues. I claim that sub-numerations do indeed constitute phases when they have been merged into the workspace, but that they are not dependent upon the merger of a specific head. Instead, when building a phase, the phase itself is not complete until the last item in the sub-numeration has been merged into the workspace, irrespective of what that last item is. This last item is given the status of phase head and the phrase it projects acts as the phase, implying that all projections below this do not have phasal status. This removes the sovereignty of $\mathrm{vP}$ acting as the clause internal phase, and allows for a variable phase boundary. $^{42}$

Of course, one may ask how the system knows when to grant the status of phase head. The answer to this is: once the sub-numeration has been exhausted. The derivational system continues to merge items from the sub-numeration until there is no more material left to (externally) merge. This tells the syntax that the sub-numeration has been exhausted and therefore that the phase is complete. Therefore the last merged item is crowned as the phase head, and the phrase it projects is the phase.

To summarise, we have arrived at the following system for variable phases:
a. Phases are determined by sub-numerations.
b. The last item from a sub-numeration to be merged into the workspace projects the phase, irrespective of what that item is.

I now show how this allows the progressive aspectual layer (but no higher aspectual material) to project the clause internal phase when present in the derivation, and vP (or VP) otherwise.

So far I have argued that the boundary for the clause internal phase is located between progressive and perfect aspect. This implies that the two sub-numerations of the main clausal spine potentially consist of the following elements:

\section{a. [Prog be, ProgAsp, Passive/Copula be/v, Voice, V] \\ b. [C, T, Modal, Inf, Perf have, PerfAsp $]$}

The most important divide here is that progressive aspect and the progressive auxiliary are contained within the first sub-numeration, along with the voice layer and the lexical verb, whilst perfect aspect and the perfect auxiliary have are contained in the second subnumeration, along with the modal layer, tense and the CP layer.

Applying the variable phase approach to this division in the sub-numerations provides us with the following phasal system: if progressive aspect is absent from the derivation, the last item to be merged from the first sub-numeration would be that of passive/copula be in $\mathrm{v}^{\circ}$, or simply $\mathrm{v}^{\circ}$ itself, depending on whether the sentence is active, passive, or a copular construction. This means that in the absence of progressive aspect, vP is the highest

\footnotetext{
${ }^{42}$ Rizzi (2005) has made similar suggestions for a variable phase boundary with respect to the CP layer.
} 
projection of the first sub-numeration, and so acts as the phase. Once vP has projected onto the workspace, we find that the first sub-numeration is exhausted and so assign $\mathrm{vP}$ its phasal status:

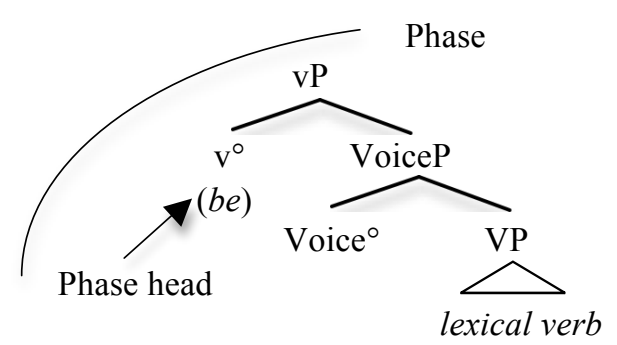

If progressive aspect is present on the other hand, the progressive auxiliary be is the last item to be merged from the first sub-numeration. Therefore, the phrase it projects, $\mathrm{vP}_{\text {prog, }}$ acts as the clause internal phase, crucially denying vP of any kind of phasal status: ${ }^{43}$

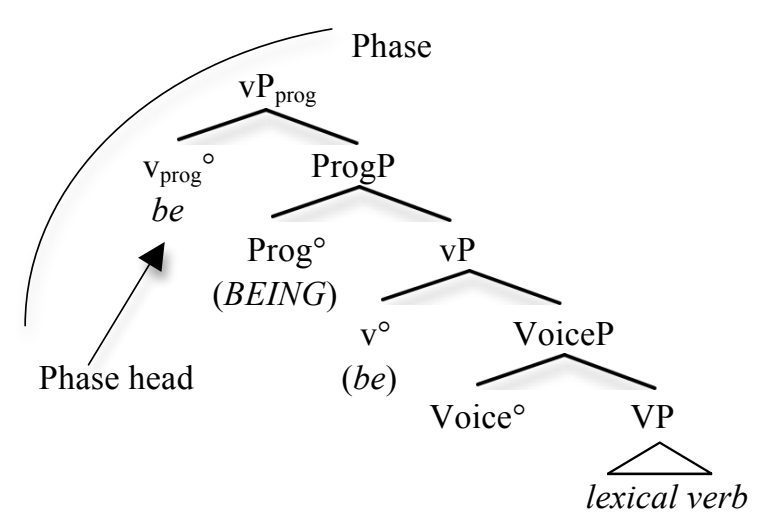

Finally, note that, if one follows Hale \& Keyser 1993 by assuming only VP to be present in unaccusative constructions, then the variable phase approach offers a means in which the clause internal phase can still project in such instances, in accordance with Legate's (2003) observations. In the case of an unnacusative (and in the absence of progressive aspect), only $\mathrm{V}$, i.e., the unaccusative verb itself, would be contained within the first sub-numeration. Therefore $\mathrm{V}$ is the first and, more importantly, last item to be merged from the subnumeration. Once VP projects, we find the sub-numeration to be exhausted and so grant VP phasal status:

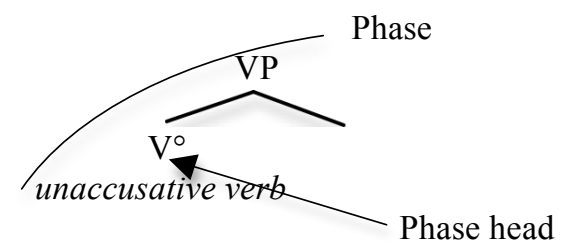

The question arises of course as to why the aspectual system should be divided in this way. That is, why should perfect aspect be contained in the second sub-numeration and therefore, the higher phase, along with tense and modality, whilst progressive aspect is contained within the first sub-numeration and therefore, the lower phase, along with voice and the lexical verb?

\footnotetext{
${ }^{43}$ Note that if perfect aspect and have were to be included within the first sub-numeration of the clause, they would constitute part of the clause internal phase when they project. Since this paper has argued at length that perfect aspect does not constitute part of the clause internal phase, but rather makes up part of the higher phase along with modals, TP and CP, this would be an undesirable consequence. Therefore perfect aspect should be consigned to the second sub-numeration of the clause.
} 
Although I have no definite solution, I tentatively propose that the first sub-numeration is made up of material that comprises the predicate layer of the clause, and that progressive aspect, yet not higher material, forms part of the predicate. In the next section I provide support for this claim.

\subsection{The progressive predicate}

There is no common consensus within the generative literature as to how large the predicational layer can be. Grimshaw $(2000,2005)$ for instance assumes that the domain of the verbal predicate can extend as far as $\mathrm{T}^{\circ}$. I follow Bowers $(1993,2001,2002)$, however, in assuming that the predicational layer generally corresponds to the $\mathrm{vP}$ domain. I furthermore assume that this predicational layer comprises the first sub-numeration. I speculate that progressive aspect, yet no higher material, is included within the first sub-numeration because it forms a part of the predicate. Indeed, Bowers (2002:204) also tentatively assumes that the progressive aspectual layer may constitute part of the predicational layer. Furthermore, Heycock (2011) has noted that progressive aspect can be co-ordinated with nominal, adjectival and prepositional predicates at the predicate level:

(86) Julia is tired and suffering from a cold and (thus) [a good candidate for a miracle cure]/[in a terrible mood].

This potentially shows the predicational nature of progressive aspect. ${ }^{44}$

Another possible indication that progressive aspect is part of the predicate is that it is the complement of be in English. This is identical in form to copular be, which appears alongside AP, DP and PP predicates. It is thus possible that progressive and passive be are simply instances of a copula selecting a verbal predicate, suggesting once again the predicational nature of the progressive. The perfect auxiliary in English, on the other hand, is have, which is rather distinct from the copular auxiliary, suggesting that perfect aspect, unlike progressive, is not a part of the predicate. ${ }^{45}$

Ramchand \& Svenonius (2013) have also presented suggestive evidence which explicitly shows that perfect aspect is contained within a higher domain of structure along with modals, which may be considered the temporal layer. This is to the exclusion of progressive aspect. Ramchand \& Svenonius note that both modals and perfect aspect allow separate temporal modification of the reference time and the event time, whilst the progressive does not:

a. Now Johnny may go to the party tomorrow.

b. When I saw him, John had spoken with her the day before.

c. * By next month, John is building a house now.

(Examples from Ramchand \& Svenonius 2013:(44) and (45))

\footnotetext{
${ }^{44}$ Potential further evidence for the predicational nature of progressive aspect is the fact that it is sensitive to lexical restrictions (Haegeman, p.c). That is, progressive aspect cannot occur with stative verbs, whilst there are no apparent lexical restrictions for perfect aspect:

(i) * John is knowing French.

(ii) John has known French (for a long time).

This suggests that progressive aspect is much more closely tied to the lexical verb/predicate than higher aspectual forms.

${ }^{45}$ Obviously many languages such a French, Dutch, Serbo-Croatian and many of the Celtic languages (to name but a few) realise perfect aspect with a copular auxiliary as well. As will be briefly discussed later, this suggests that certain languages are able to include perfect aspect within the predicate, causing a larger clause-internal phase than in English. This may be a point of cross-linguistic variation.
} 
This is at least suggestive that modals and perfect aspect constitute part of what we may term the temporal domain, whilst progressive aspect is contained with the lower, predicational domain.

This evidence together may therefore indicate the reason why progressive aspect is contained within the first sub-numeration of the main clausal spine, and so constitutes part of the clause internal phase when it projects. Of course, this is a tentative claim that requires further research. At present, whilst I have offered a reasonable formalisation of how a variable phase boundary can be made possible, it remains a stipulation that the sub-numerations should be divided in the way I have argued and requires further research to understand exactly why they should be divided in this way. In the next section I discuss previous attempts at establishing a dynamic approach to phases.

\subsection{Prior approaches to dynamic phases}

To summarise, I have shown how a variable phase boundary can be achieved within the Minimalist Framework, and all that is needed to achieve this is the rule in (81), repeated here:

(88) a. Phases are determined by sub-numerations.

b. The last item from a sub-numeration to be merged into the workspace projects the phase, irrespective of what that item is.

This system is not too dissimilar from the dynamic approach to phases as argued for by Bobaljik \& Wurmbrand (2005), Wurmbrand (2012, to appear) and Bošković (to appear a, b). Bobaljik \& Wurmbrand (2005) argue that phases should be context dependent. Wurmbrand (2012, to appear) has claimed that aspectual layers should be contained within the clause internal phase when such projections are present in the derivation, whilst Bošković (to appear $a, b)$ has formalised this by proposing a dynamic approach to phases known as the 'highest phrase is a phase' approach. To close this section I provide a brief discussion of Bošković's (to appear a) proposal.

Whilst the approach I advocate in this paper defines the phase boundary as being determined by the last item to be merged from the sub-numeration, irrespective of what that item is, Bošković's (to appear a) 'highest phrase is a phase' approach instead defines the phase boundary as being demarcated by the highest functional category within the extended projection (Grimshaw 2000, 2005) of a lexical item. That is, the lower bound of each phase is always determined by a lexical item, whether that be a verb, preposition, noun, adjective or adverb, whilst the higher bound of the phase is demarcated by the highest functional projection to be merged in the functional sequence stemming from the lexical item. In the case of the clause internal phase, its lower bound is demarcated by either the verbal, prepositional, adjectival or nominal lexical predicate of the clause. The higher bound is demarcated by the final functional projection to be merged into the extended projection line of that lexical predicate. In the absence of any aspectual layers, this would be $\mathrm{v}^{\circ}$. However, the aspectual layers are also part of the extended domain of the lexical predicate, meaning that when progressive aspect projects, this would be the highest functional projection, and so would act as the phase. If perfect aspect is present, this would be the clause internal phase since it is merged higher than progressive aspect, yet is still a part of the extended projection of the lexical predicate. ${ }^{46}$

Bošković (to appear a) uses this approach to also provide an account of the auxiliary ellipsis paradigm in English VPE that was discussed in sections 3.2 and 3.3. Here I provide a

\footnotetext{
${ }^{46}$ A problem with this analysis that Bošković himself notes is that if the lower bound of every phase is demarcated by a lexical item, what serves as the lower bound of the CP phase? TP is obviously not a lexical item, and there does not in fact appear to be any consistent lexical item which can act as the lower bound of this phase.
} 
critical overview of Bošković's analysis, outlining why the account offered in this paper should be preferred (see also the critical analysis of Aelbrecht \& Harwood (2013), which provides a thorough discussion of all attempts to explain the auxiliary ellipsis paradigm of English).

Labelling aside, Bošković essentially assumes the same functional hierarchy that was established in (7), and also assumes the same analysis with regards to auxiliary raising (though he motivates this through a morphological requirement rather than through feature checking). A WYSIWYG approach is also adopted. As previously mentioned in this paper, Bošković also claims that ellipsis may target either the phasal complement, or an entire phase.

In the absence of any aspectual projections, Bošković takes vP to act as the clause internal phase, as also claimed in this paper. This implies that, under VPE, ellipsis is able to target either the entire vP phase, or the phasal complement of VP (there is no VoiceP intervening between vP and VP in his system). Similar to the analysis advocated in this paper, Bošković claims that the lexical verb does not raise to vP (at least in ellipsis contexts in his account, following Lasnik (1999)), therefore it never escapes the ellipsis site.

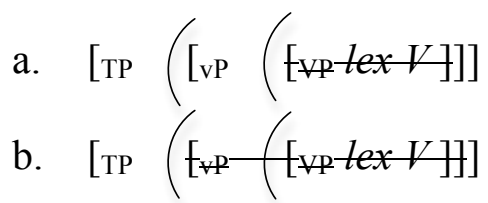

As previously stated, progressive aspect, being part of the extended projection of the lexical predicate, extends the size of the clause internal phase when it projects. However, Bošković claims that when the progressive aspectual layer is present, ProgP acts as the clause internal phase rather than the $\mathrm{vP}_{\text {prog }}$ shell above it. This is the first fundamental problem with his account: vP shells also form part of the extended projection under Bošković's assumptions, and in the absence of any higher aspectual material, $\mathrm{vP}_{\text {prog }}$ would constitute the highest projection in the extended domain of the lexical verb. So it is a mystery why ProgP should in fact act as the clause internal phase rather than the $\mathrm{vP}_{\text {prog }}$ shell. Moreover, by allowing ProgP to act as a phase and not the vP shell above it, we are separating aspects and their associated auxiliaries by a phasal boundary. As was stated earlier, auxiliaries are always closely tied to their aspectual forms: whenever $\mathrm{vP}_{\text {prog }}$ is present, so is $\operatorname{Prog} \mathrm{P}$, or whenever $\mathrm{vP}_{\text {perf }}$ is present, so is PerfP. It seems strange then that the auxiliary in $\mathrm{v}_{\text {prog }}$ should be separated from its aspect in ProgP by a phase boundary, as Bošković implies.

These matters aside, with ProgP acting as the phase VPE has the option of privileging either the entire ProgP phase itself, or the vP phasal complement. In order to account for the obligatory ellipsis of being, Bošković then claims that being is the only auxiliary that does not raise for inflectional purposes and instead has its inflection lowered onto it in its $\mathrm{v}^{\circ}$ base position. The reason for this is clear: if being rose to $\mathrm{Prog}^{\circ}$ for inflectional purposes, it is predicted to only be optionally elided. In order for being to remain consistently in the ellipsis site, Bošković is forced to claim that being does not raise from its base position.

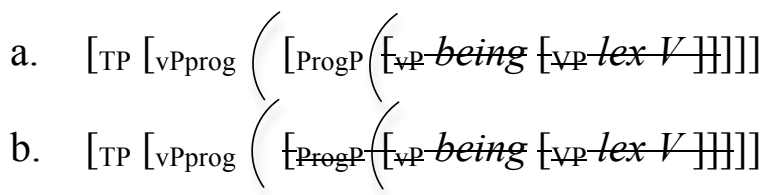

However, as this paper has already argued, there is no principled reason as to why being should be the only auxiliary not to raise and is therefore a pure stipulation.

In the presence of perfect aspect, which Bošković also assumes to constitute part of the extended projection of the lexical verb, PerfP acts as the clause internal phase. Again, the $\mathrm{vP}_{\text {perf }}$ shell above PerfP curiously does not act as the phase. This implies that VPE may target either the PerfP phase itself, or the complement of PerfP ( $\mathrm{vP}_{\text {prog }}$ or $\mathrm{vP}$, depending on whether the progressive aspectual layer is present or not). The optional deletion of been now falls out 
of this analysis: been raises for inflectional purposes to Perf ${ }^{\circ}$, which is optionally targeted by ellipsis.

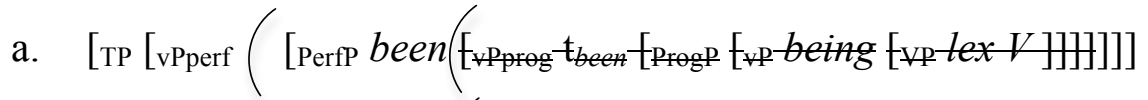

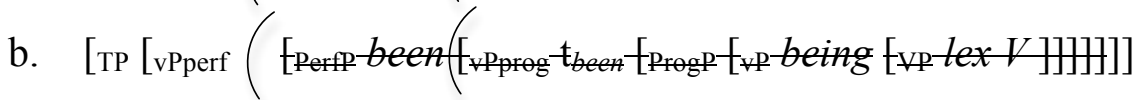

The analysis however has very little to say about the optional ellipsis of be and so is generally unable to capture the entire auxiliary ellipsis paradigm. Bošković tentatively claims in a footnote that InfP, the landing site of be, could also potentially act as the clause internal phase when it projects, meaning ellipsis could target either InfP or its complement, therefore possibly capturing the optional ellipsis of be. However, $\mathrm{Inf}^{\circ}$ is also the landing site of have, meaning we would predict optional ellipsis of have to be as widely available as the optional ellipsis of be. As was argued in section 3.2.3 however, ellipsis of have is highly unstable and restricted and often rejected, something which Bošković's proposal would be unable to capture if it tried to seriously explain the ellipsis of be. Moreover, if in the presence of InfP the complement of Inf ${ }^{\circ}$ must always be elided under VPE, we should expect everything below the infinitival auxiliary to be obligatorily elided under ellipsis. Consider, however, (92), with non-finite have in $\operatorname{Inf}^{\circ}$, and been in Perf ${ }^{\circ}$, in the complement of Inf $^{\circ}$. Here one incorrectly expects been to be obligatorily elided.

(92) John could have been defeated, and Peter could have (been) defeated too.

These issues, when taken together, mean that Bošković's approach does not correctly capture the auxiliary ellipsis paradigm of English.

Abstracting away from these matters, the most fundamental problem with the 'highest phrase is a phase' approach is that it is unable to capture the unique behaviour of progressive aspect that sets it apart from higher aspectual forms in English. That is, the 'highest phrase is a phase' approach is unable to exclude perfect aspect from the clause internal phase, something which this paper argues is necessary in order to explain many of the quirks that only progressive aspect exhibits. For this reason I maintain that the variable phase approach advocated in this paper is better suited for explaining the English data since it is able to capture the aspectual divide that I have shown to exist not only in VPE, but also VPF phenomena and idiomatic constructions (and in section 7, existentials). ${ }^{47}$

In the next section I show how existential constructions, under Chomsky's (2000, 2001) analysis, add further support to the notion that progressive aspect is the clause internal phase (when present).

\section{Existential Constructions and Phases}

The data discussed so far shows that progressive aspect shares a number of unique properties with the lexical verb and its arguments to the exclusion of higher aspectual forms, leading us to conclude that the progressive aspectual layer acts as the clause internal phase when present in the derivation. A question that one might ask at this point is, if the progressive aspectual layer does genuinely project the clause internal phase in English, shouldn't we be able to observe edge effects at the periphery of the progressive aspectual layer? The answer is that we do potentially see such edge effects, namely in English existential constructions, to which I return in this section. Consider the following sentence:

\footnotetext{
${ }^{47}$ Despite these differences I am grateful to the 'highest phrase is a phase' approach which has been rather influential in the writing of this paper, and generally the two approaches sit in line with a move towards a more dynamic understanding of phases.
} 
The standard Minimalist analysis for this sentence is that the derived subject is merged as complement of $\mathrm{V}^{\circ}$. It surfaces in the canonical subject position by first raising through the clause internal phase edge (Spec-vP according to Chomsky 2000, 2001), and then raising to Spec-TP to satisfy the EPP feature. Consider, however, the distribution of a derived subject in an existential construction:

There were several men arrested for drunkenness.

Recall from the discussion in section 3.1 that in this sentence the expletive there occupies Spec-TP, preventing the derived subject from raising to this position. However, given that the derived subject is not occupying its base, post-verbal position, but occurs pre-verbally, it must have undergone some form of intermediate raising. As previously discussed, Chomsky (2000, 2001) analyses this sort of construction as involving stranding of the subject on the clause internal phase edge. Here I show in more detail how the derivation proceeds under Chomsky's assumptions (and under a minimal C-T-v-V structure):

(i) The first phase is built up using material from the first sub-numeration up to the point when $\mathrm{v}^{\circ}$ is merged, thereby completing the phase. The derived subject is merged as complement of $\mathrm{V}^{\circ}$.

(ii) Bearing unchecked Nominative Case features, the subject must undergo further operations in the higher phase. Therefore, the derived subject raises to Spec-vP, the phase edge.

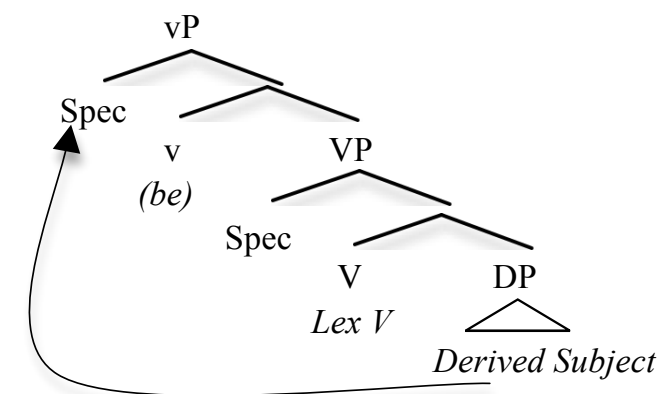

(iii) The second phase is then constructed. Once $\mathrm{T}$ is merged we have an EPP feature to check. There are two ways of checking this feature: either the subject in Spec-vP raises to Spec-TP, or the expletive there, contained in the second sub-numeration, is merged directly into Spec-TP. Since external Merge takes priority over Move, it is less costly to Merge the expletive into this position than to Move the subject. Therefore, expletive there is merged from the second sub-numeration into Spec-TP, satisfying the $\mathrm{EPP}$ on $\mathrm{T}^{\circ}$. The subject is therefore stranded in the Spec-vP phase edge, where it has its Case feature checked by $\mathrm{T}^{\circ}$ via Agree and subsequently values T's phi-features in the process. Sitting on the Spec-vP phase edge, the subject precedes the lexical verb, but is situated below material in $\mathrm{T}^{\circ}$.

Consider now the distribution of the derived subject in light of a more articulated structure:

(96) a. There were many people being arrested for drunkenness.

b. There have been many people arrested for drunkenness.

c. There will be many people arrested for drunkenness.

The crucial fact here is that the subject must precede being but follow be/been: 
If being surfaces in $\operatorname{Prog}^{\circ}$ as argued for in this paper, then the subject must be occupying a position higher than Spec-vP in order to precede this auxiliary. The question then is which position has the subject raised to, and why? Since the subject follows be, which I have argued to occupy $\operatorname{Inf}^{\circ}$, we can rule out the subject occupying Spec-InfP. Even more crucially however, since the subject follows been, which I have argued to surface in Perf ${ }^{\circ}$, we can rule out the subject occupying Spec-PerfP. Given the structural hierarchy we posited in (7) and (9), the only two other positions available are $\mathrm{Spec}-\mathrm{Prog} \mathrm{P}$ and $\mathrm{Spec}-\mathrm{v} \mathrm{P}_{\text {prog. }}$.

Note that if $\mathrm{vP}_{\text {prog }}$ projects the clause internal phase when present, as I have argued, then Spec- $\mathrm{vP}_{\text {prog }}$ would act as the clause internal phase edge. This potentially gives us a position for the subject to raise to that would automatically explain the distribution of the subject, and would furthermore provide a motivation for this movement. Following Chomsky's basic analysis the subject, driven by a need to check its Case feature, raises to the Spec-v $\mathrm{P}_{\text {prog }}$ phase edge so as to escape spell-out and ultimately get its feature checked in the higher phase. Obviously the subject in existential constructions does not raise any higher than this since merger of there in Spec-TP blocks any further movement of the subject and strands it on the clause internal phase edge. Finally, with the subject occupying the Spec-v $\mathrm{P}_{\text {prog }}$ position, it correctly precedes being, but follows be and been.

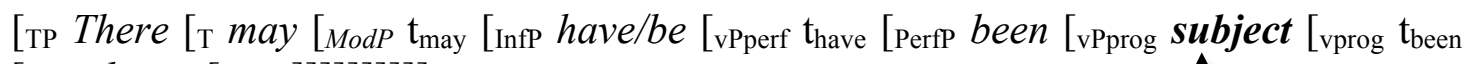

$$
\begin{aligned}
& \text { [ProgP being [vP ...]]]]]]]]]] }
\end{aligned}
$$

Thus, the variable phase approach as argued for in this paper correctly explains the distribution of existential subjects without having to resort to any additional mechanisms.

Note furthermore that if the perfect aspectual layer constituted part of the clause internal phase as argued by Wurmbrand (2012, to appear) and Bošković (to appear a), we would expect the subject to raise to the edge of this layer, incorrectly predicting existential subjects to precede been as well as being. This provides further evidence to suggest that perfect aspect, unlike progressive aspect, is not contained within the clause internal phase.

Of course, a lot of work still needs to be done on the topic of existentials for such an analysis to go through. For starters, the aspectual restrictions of unaccusative, transitive and ditransitive existential constructions, as discussed in section 3.2, still need accounting for (see Deal 2009 and Harwood 2011 for attempted explanations). Furthermore, an explanation still needs to be given for how post-verbal subjects in unaccusative existentials can be derived:

(99) a. There arrived several letters.

b. There have arrived several letters.

c. There will arrive several letters.

Here we still predict a VP or vP phase to be projected, to the specifier of which the subject should raise in order to escape spell out, leading us to predict that the subject should surface in pre-verbal position, contrary to fact. It is interesting to note though that when progressive aspect is present on the unaccusative verb, edge effects are once again observable. That is, the subject appears in pre-verbal position:

(100) There were several letters arriving (all at the same time).

These matters aside, when one considers the facts in detail, Chomsky's $(2000,2001)$ phasebased analysis of English existential constructions actually seems to lend independent support to the variable phase approach argued for in this paper. 
In the next section I briefly address a number of further issues.

\section{Further Issues}

In section 6 , the issue was raised that it is not yet entirely clear why progressive aspect should be contained within the first sub-numeration, whilst higher aspectual material is contained in the second. Some evidence tentatively suggests that progressive aspect constitutes part of the predicational layer to the exclusion of higher aspectual forms, and that this is the reason for such a divide, although ultimately a topic for further research is to better understand why this division in the aspectual hierarchy should exist. It is possible that the answer lies in the semantics, though this is beyond the scope of the current paper.

In the remainder of this section I briefly address two further issues that the analysis in this paper raises. First, I discuss the cross-linguistic implications of the analysis, and then I further discuss the notion suggested in 3.1 that phase heads are derived from overlapping domains.

The first issue to be addressed is how exactly the conclusions drawn from this paper carry over cross-linguistically. There is evidence to suggest that progressive aspect, but no higher aspectual forms, should be included in the clause internal phase in languages other than English. Sailor \& Kuo (2010) for instance, have claimed that VPE in Taiwanese appears to target the progressive aspectual layer, whilst Aboh (2005) and McCloskey (2012) have observed phase edge effects in the presence of progressive aspect in languages as disparate as Gungbe and Irish. This potentially suggests that the separation of the aspectual hierarchy in the way I have argued for is more than just a language specific property of English, although far more work needs to be done on these languages before any reasonable conclusions can be drawn. I do not claim, however, that this separation in the aspectual hierarchy is necessarily a universal property. There are obviously many languages that do not realise progressive aspect, in which case it is currently unclear where the clause internal phase boundary may lie in such languages. Furthermore, the diagnostics I have used for English to demonstrate that progressive aspect projects the clause internal phase when present suggest, when applied cross-linguistically, that some languages may include as much as perfect aspect within the clause internal phase. Rocquet (2010) for instance, motivated by data from past participle agreement, has argued that perfect aspect should be included in the clause internal phase for French, and with regards to VPE, there are many languages which appear to demonstrate ellipsis of perfect aspect, contrary to the English and Taiwanese data. Rouveret (2012) shows that this is potentially the case for Welsh, and Aelbrecht (2010) for Dutch Modal Complement Ellipsis. I suggest therefore that the size of the clause internal phase may vary crosslinguistically, and leave this for further research.

A second issue to be addressed is the point established in section 3.1 that ellipsis appears to optionally target either the phasal complement, or the entire phase, which contradicts Gengel's $(2007,2008)$ initial claim that ellipsis is non-pronunciation at PF of the phasal spellout domain, i.e., the phasal complement. In order to explain the possibility of full phasal ellipsis, it was assumed that full phasal spell out must sometimes be possible. To understand this, I tentatively expanded on a claim made by Bobaljik \& Wurmbrand (2005) in which it was proposed that phase heads and their specifiers are domains of overlap between two phases. That is, the phase head and its specifiers are simultaneously selected by both the lower and higher phases and share properties with both, meaning there may be a degree of optionality as to whether the phase head and its specifiers spell out with the first phase or the second phase. This may be compatible with a traditional, rigid approach to phases in which $\mathrm{v}^{\circ}$ always acts as the clause internal phase, in which case $\mathrm{v}^{\circ}$ would always be selected by both the first and second sub-numerations of the clause. There is a tension, however, between the notion of overlapping domains and the variable phase approach I have proposed in this paper, since the phase head is never fixed. If one wished to maintain the notion of both a variable phase boundary, and overlapping domains, one would have to claim that sometimes $\mathrm{v}_{\mathrm{prog}}{ }^{\circ}$, when present, is simultaneously selected by the first and second sub-numerations, but nothing 
else, but that in the absence of progressive aspect, $\mathrm{v}^{\circ}$ is simultaneously selected by both subnumerations. This is an undesirable consequence. Presently I have no means of resolving this tension and leave it as a matter for future research.

In the final section I summarise the main arguments of the article.

\section{Summary and Conclusion}

This paper has aimed to show that progressive aspect shares a number of unique properties with the lexical verb and its arguments to the exclusion of higher aspectual forms. This can be seen in VP ellipsis, VP fronting phenomena, idioms and existential constructions in English. I have analysed this apparent divide in the aspectual hierarchy as an indication that progressive aspect, yet no higher aspectual forms, should be a part of the clause internal phase. Under the assumption that aspectual projections are not always present in the underlying derivation, this kind of separation is allowed for if one supposes a variable phase approach in which the last merged item from a sub-numeration projects the phase, irrespective of what that item is. If progressive aspect, yet no higher aspectual forms, is contained within the same subnumeration as the lexical verb, and is merged after $\mathrm{v}$, this denies $\mathrm{vP}$ of its perpetual status as the clause internal phase and allows the progressive aspectual layer to take on the properties of the clause internal phase when present. When progressive aspect is not present, however, $\mathrm{vP}$ acts as the phase as standardly assumed. This split in the aspectual hierarchy I argued to be due to progressive aspect forming a part of the predicational layer in English, whilst perfect aspect does not.

At the very least, this paper has set out to demonstrate the uniqueness of progressive aspect. That is, in English, there appears to be a split in the structural hierarchy in which progressive aspect, and everything below it, can be considered a discrete unit of structure, separate from perfect aspect and all projections above it. Even if one would rather not define this split in terms of phases, I have hopefully at least shown this aspectual divide in English to be genuine.

\section{References}

Abels, Klaus. 2003. Successive cyclicity, anti-locality, and adposition stranding. Doctoral dissertation, University of Connecticut, Storrs.

Aboh, Enoch. 2005. Object shift, verb movement and verb reduplication. In G. Cinque \& R. Kayne eds., The Oxford handbook of comparative syntax. 138-177. New York: OUP.

Aelbrecht, Lobke. 2010. The syntactic licensing of ellipsis. Amsterdam: John Benjamins.

Aelbrecht, Lobke. 2012. What ellipsis can do for phases and what it can't, but not how. Talk presented at Ellipsis conference, Vigo University.

Aelbrecht, Lobke \& Marcel den Dikken. To appear. Preposition doubling in Flemish and its consequences for the syntax of Dutch PPs. Journal of comparative Germanic linguistics.

Aelbrecht, Lobke \& William Harwood. 2013. To be or not to be elided. lingbuzz/001609.

Akmajian, Adrian, Susan Steele \& Thomas Wasow. 1979. The category AUX in Universal Grammar. Linguistic Inquiry 10. 1-64.

Akmajian, Adrian \& Thomas Wasow. 1975. The constituent structure of VP and AUX and the position of the verb be. Linguistic Analysis 1. 205-245.

Baker, Mark. 1997. Thematic roles and syntactic structure. In Liliane Haegeman ed., Elements of grammar. 73-137. Dordrecht: Kluwer.

Baker, Mark C. 2003. Building and merging, not checking: the nonexistence of (Aux)-S-V-O languages. Linguistic Inquiry 33. 321-328.

Baltin, Mark. 2006. The nonunity of VP-preposing. Language 82: 734-766.

Baltin, Mark. 2007. The position of adverbials. In Phrasal and clausal architecture: Syntactic derivation and interpretation, eds. Vida Samiian Simin Karimi and Wendy K. Wilkins, 2539. Amsterdam: John Benjamins.

Baltin, Mark. 2012. Deletion versus pro-forms: an overly simple dichotomy? Natural 
Language and Linguistic Theory 30. 381-423.

Bjorkman, Bronwyn. 2011. BE-ing default: the morphosyntax of auxiliaries. Doctoral dissertation, MIT.

Blom, Alied and Saskia Daalder. 1977. Syntaktische theorie en taalbeschrijving. Muiderberg: Coutinho.

Bobaljik, Jonathan. 1994. What does adjacency do? In Heidi Harley and Colin Phillips, eds., The morphology-syntax connection. MITWPL 22. Cambridge, MA: MITWPL.

Bobaljik, Jonathon. 2001. Floating quantifiers: handle with care. In Lisa Cheng and Rint Sybesma, eds., The Second GLOT International State-of-the-Article Book. 107-148. Mouton de Gruyter.

Bobaljik, Jonathan \& Susi Wurmbrand. 2005. The domain of agreement. Natural Language and Linguistic Theory 23. 809-865.

Bošković, Željko. 2004. Be careful where you float your quantifiers. Natural Language and Linguistic Theory 22. 681-742.

Bošković, Željko. 2007. On the locality and motivation of Move and Agree: an even more minimal theory. Linguistic Inquiry 38. 589-644.

Bošković, Zeljko. 2011. Rescue by PF deletion, traces as (non)-interveners, and the that-trace effect. Linguistic Inquiry 42.

Bošković, Željko. To appear a. Now I'm a phase, now I'm not a phase: on the variability of phases with extraction and ellipsis. Linguistic Inquiry.

Bošković, Željko. To appear b. Phases beyond clauses. In Lilia Schürcks, Anastasia Giannakidou, Urtzi Etxeberria and Peter Kosta, eds., Nominal Constructions in Slavic and Beyond. De Gruyter.

Bowers, John. 1993. The syntax of predication. Linguistic Inquiry 24. 591-656.

Bowers, John. 2001. Predication. In Mark Baltin and Chris Collin, eds., The handbook of contemporary syntactic theory. Oxford: Blackwell. 299-333.

Bowers, John. 2002. Transitivity. Linguistic Inquiry 33. 183-224.

Butler, Jonny. 2004. Phase structure, phrase structure, and quantification. Doctoral dissertation, University of York.

Caponigro, Ivano \& Carson T. Schütze. 2003. Parameterizing passive participle movement. Linguistic Inquiry 34. 293-307.

Chomsky, Noam. 1972. Some empirical issues in the theory of transformational grammar. In Paul Stanley Peters, ed., Goals of linguistic theory. Englewood Cliffs: Prentice-Hall Inc.

Chomsky, Noam. 1980. Rules and representations. Columbia University Press, New York.

Chomsky, Noam. 1981. Lectures on government and binding. Foris, Dordrecht.

Chomsky, Noam. 1986. Barriers. Cambridge, MA: MIT Press.

Chomsky, Noam. 1993. A minimalist program for linguistic theory. In Ken Hale and Samuel J. Keyser, eds., The View from Building 20: Essays in Linguistics in Honor of Sylvain Bromberger. 1-25. Cambridge, MA: MIT Press.

Chomsky, Noam. 1995. The Minimalist Program. Cambridge, MA: MIT Press.

Chomsky, Noam. 2000. Minimalist inquiries: the framework. In R. Martin, D. Michaels and J. Uriagereka, eds., Step by Step: essays on minimalist syntax in honor of Howard Lasnik. 89155. Cambridge: MIT Press.

Chomsky, Noam. 2001. Derivation by phase. In M. Kenstowicz ed., Ken Hale: a life in language, 1-52. Cambridge: MIT Press.

Chomsky, Noam. 2005. On phases. In R. Freidin, C. P. Otero, and M. L. Zubizarreta eds., Foundational issues in linguistic theory: Essays in honor of Jean Roger Vergnaud. 133166. Cambridge: MIT Press.

Chomsky, Noam and Howard Lasnik. 1993. The theory of principles and parameters. In Joachim Jacobs, Arnim von Stechow, Wolfgang Sternefeld and Theo Vennemann, eds., Syntax: an international handbook of contemporary research, Volume 1. 506-569. Berlin: Walter de Gruyter. 
Cinque, Guglielmo. 1999. Adverbs and functional heads: a cross-linguistic perspective. Oxford: OUP.

Cirillo, Robert. 2009. The Syntax of Floating Quantifiers: stranding revisited. Doctoral Dissertation, Universiteit van Amsterdam.

van Craenenbroeck, Jeroen. To appear. The Syntax of Ellipsis: evidence from Dutch dialects. New York: OUP.

Deal, Amy Rose. 2009. The origin and content of expletives: evidence from "selection". Syntax 12.

Declerck, Ranaat. 1988. Studies on copular sentences, clefts and pseudo-clefts. Leuven: Leuven University Press/Foris Publications.

Dikken, Marcel den. 1995. Copulas. Ms. Vrije Universiteit Amsterdam/HIL.

Dikken, Marcel den. 2006. Specificational copular sentences and pseudo-clefts. In Martin Everaert and Henk van Riemsdijk, eds., The Blackwell companion to syntax, 4. Blackwell Publishing.

Dikken, Marcel den. 2007. Phase extension: contours of a theory of the role of head movement in phrasal extraction. Theoretical Linguistics 33. 1-41.

Eide, Kristin \& Tor Åfarli. 1997. A predication operator: evidence and effects. Ms. Department of linguistics, NTNU.

Einarsson, Stefán. 1945. Icelandic: grammar, texts, glossary. Baltimore: The John Hopkins Press.

Emonds Joseph. 1976. A transformational approach to English syntax: root, structurepreserving, and local transformations. New York: Academic Press.

Fowlie, Meaghan. 2010. More multiple multiple spell-out. In Proceedings of GLOW 31: principles of linearisation workshop. Berlin: Mouton de Gruyter.

Fox, Danny and David Pesetsky. 2003. Cyclic linearisation and the typology of movement. Ms. MIT.

Fox, Danny and David Pesetsky. 2005. Cyclic linearization of syntactic structure. Theoretical Linguistics 31. 1-45.

Gallego, Ángel. 2010. Phase Theory. Amsterdam: John Benjamins.

Gengel, Kirsten. 2007. Phases and ellipsis. In Emily Elfner and Martin Walkow, eds., Proceedings of the $37^{\text {th }}$ meeting of the North East Linguistic Society. GLSA: University of Massachusetts, Amherst.

Gengel, Kirsten. 2008. Phases and ellipsis. Linguistic Analysis 35. 21-42.

Grimshaw, Jane. 2000. Locality and extended projection. In Peter Coopmans, Martin Everaert and Jane Grimshaw, eds., Lexical specification and insertion. Amsterdam/Philadelphia: John Benjamins. 115-133.

Grimshaw, Jane. 2005. Words and Structure. Chicago: CSLI Publications.

Hale, Ken \& Samuel Jay Keyser. 1993. On argument structure and the lexical expression of syntactic relations. In Ken Hale and Samuel Jay Keyser, eds., The View From Building 20. Cambridge: MIT Press. 53-109.

Haegeman, Liliane. 2008. Speculations on subject positions, predication and predicate inversion in English. Ms. Ghent University.

Harwood, William. 2011. Phasage: a phase based account of English existential constructions. Proceedings of the $13^{\text {th }}$ Seoul International Conference on Generative Grammar. Seoul: Hankuk Publishing

Heggie, Lorie. 1988. The syntax of copular structures. Diss., University of Southern California.

Henry, Alison \& Siobhan Cottell. 2007. A new approach to transitive expletives: evidence from Belfast English. English Language and Linguistics, 11.

Heycock, Caroline. 1994. The internal structure of small clauses. Proceedings of NELS 25. Amherst: GLSA. 223-238.

Heycock, Caroline. 2011. The strangeness of specificational sentences. Lecture given at 
Ghent University.

Heycock, Caroline and Anthony Kroch. 1999. Pseudo-cleft connectivity: implications for the LF interface. Linguistic Inquiry 30:3. 365-397.

Higgins, Francis. R. 1979. The pseudo-cleft construction in English. New York: Garland.

Holmberg, Anders. 1999. Yes and No in Finnish: ellipsis and cyclic spell-out. MIT Working Papers in Linguistics, Volume 33.

Holmberg, Anders. 2001. The syntax of Yes and No in Finnish. Studia Linguistica 55. 140174.

Hooper, Joan and Sandra Thompson. 1973. On the applicability of root transformations. Linguistic Inquiry 4. 465-497.

Iwakura, Kunihiro. 1977. The auxiliary system in English. Linguistic Analysis 3, 101-136.

Jackendoff, Ray. 1997. The architecture of the language faculty. MIT Press, Cambridge, Ma.

Johnson, Kyle. 1988. Verb raising and "have". McGill Working Papers in Linguistics 6: special issue on comparative Germanic syntax. 156-167.

Johnson, Kyle. 2001. What VP-ellipsis can do, and what it can't, but not why. In Mark Baltin \& Chris Collins eds., The handbook of contemporary syntactic theory. 439-479. Oxford/Boston: Blackwell.

Johnson, Kyle. 2004. How to be quiet. In Nikki Adams, Adam Cooper, Fey Parrill and Thomas Wier, eds., Proceedings from the $40^{\text {th }}$ annual meeting of the Chicago Linguistics Society. 1-20.

Kayne, Richard. 1997. The English complementizer of. The Journal of Comparative Germanic Linguistics 1. 43-54.

Kidwai, Ayesha. 2010. The cartography of phases: fact and inference in Meiteilon. In Di Sciullo, Anna Maria and Virginia Hill, eds., Edges, heads, and projections: interface properties. Amsterdam: John Benjamins 233-262.

Kim, Sum-Woong. 2009. Sloppy/strict identity, empty objects, and NP ellipsis. Journal of East Asian Linguistics 8. 255-284.

Koopman. 2010. Prepositions, postpositions, circumpositions, and particles. In Guglielmo Cinque and Luigi Rizzi, eds., Mapping spatial PPs: the cartography of syntactic structures, vol. 6. Oxford: OUP.

Koulidobrova, Elena V. 2011. Why choose a language and what happens if you don't: Evidence from bimodal bilinguals. Doctoral dissertation, University of Connecticut, Storrs.

Lasnik, Howard. 1995a. A note on pseudogapping. In Papers on Minimalist Syntax: MIT working papers in linguistics 27. 143-163.

Lasnik, Howard. 1995b. Verbal morphology: syntactic structures meets the minimalist program. In Hector Campos \& Paula Kempchinsky eds., Evolution and revolution in linguistic theory: essays in honor of Carlos Otero. 251-275. Georgetown University Press.

Lasnik, Howard. 1999. Pseudo-gapping puzzles. In Elabbas Benmamoun and Shalom Lappin, eds., Fragments: studies in ellipsis and gapping. Oxford: OUP. 141-174.

Lasnik, Howard. 2001a. Derivation and representation in modern transformational syntax. In Mark Baltin and Chris Collins, eds., Handbook of syntactic theory. 62-88. Oxford: Blackwell.

Lasnik, Harwood. 2001b. When can you save a structure by destroying it? In Minjoo Kim \& Uri Strauss, eds., Proceedings of the North East Linguistics Society 31. GLSA. 301-320.

Law, P. 1999. On the passive existential constructions. Studia Linguistica 53. 183-208.

Legate, Julie Anne. 2003. Some interface properties of the phase. Linguistic Inquiry 34. 506515.

Lobeck, Anne. 1987. Syntactic constraints on VP ellipsis. Doctoral dissertation, University of Washington, Seattle. Published, Bloomingtom: Indiana University Linguistics Club.

Lockwood, W. B. 1977. An Introduction to Modern Faroese. Tórshavn: Føroya Skúlabókagrunnar.

Marantz, Alec. 1984. On the nature of grammatical relations. Linguistic Inquiry 10. MIT 
Press, Cambridge, Ma.

Marantz, Alec. 1988. Clitics, morphological merger, and the mapping to phonological structure. In Michael Hammond and Michael Noonan, eds., Theoretical morphology. New York: Academic Press. 253-270.

McCloskey, Jim. 2012. Objecthood in Irish and the origin point of subjects. Paper presented at GIST 6: Complementiser agreement and subjects workshop, Ghent University.

McNally, Louise. 1992. An interpretation for the English existential construction. Doctoral dissertation, University of California, Santa Cruz.

Merchant, Jason. 2001. The syntax of silence: sluicing, islands and the theory of ellipsis. Oxford: OUP.

Merchant, Jason. 2004. Fragments and ellipsis. In Linguistics and Philosophy 27. Kluwer Academic Publishers. 661-738.

Merchant, Jason. 2008. An asymmetry in voice mismatches in VP-ellipsis and pseudogapping. Linguistic Inquiry 39:1. 169-179.

Merchant, Jason. To appear. Voice and ellipsis. Linguistic Inquiry 44:1.

Milsark, Gary. 1974. Existential sentences in English. Doctoral dissertation, MIT.

Moro, Andrea. 1997. The raising of predicates: predicative noun phrases and the theory of clause structure. CUP, Cambridge.

Müller, Gereon. 2011. Constraints on Displacement. A Phase-Based Approach. Amsterdam: John Benjamins.

Oku, Satoshi. 1998. A theory of selection and reconstruction in the minimalist perspective. PhD diss, University of Connecticut, Storrs.

Ramchand, Gillian \& Peter Svenonius. 2013. Deriving the functional hierarchy. Paper presented at GLOW 36.

Rezac, Milan. 2006. The interaction of Th/Ex and locative inversion. Linguistic Inquiry 37. 685-697.

Richards, Marc. 2007. On feature inheritance: an argument from the phase impenetrability condition. Linguistic Inquiry 38. 563-572.

Richards, Marc. 2011. Deriving the edge: what's in a phase? Syntax 14:1. 74-95.

Rizzi, Luigi. 1997. The fine structure of the left periphery. In Liliane Haegeman, ed., Elements of grammar. Kluwer: Dordrecht. 281-337.

Rizzi, Luigi. 2005. Phase theory and the privilege of the root. In Hans Broekhuis, Norbert Corver, Riny Huybregts, Ursula Kleinherz and Jan Koster, eds., Organizing grammar: studies in honor of Henk van Riemsdijk. Berlin: Mouton de Gruyter. 529-537.

Roberts, Ian. 1998. Have/be raising, move F, and procrastinate. Linguistic Inquiry 29:1. 113125.

Roberts, Ian. 2010. A deletion analysis of null subjects. In Theresa Biberauer, Anders Holmberg, Ian Roberts, and Michele Sheehan, eds., Parametric variation: Null subjects in minimalist theory. Cambridge: CUP. 58-87

Rocquet, Amelie. 2010. Past participle agreement in French: a matter of phases and caseaccessibility. In D. K. An. \& S. Y. Kim eds., Movement in minimalism: Proceedings of the $13^{\text {th }}$ Seoul International Conference on Generative Grammar. Seoul: Hankuk Publishing.

Ross, John Robert. 1969. Guess who? In Robert I. Binnick, Alice Davison, Georgia M. Green and Jerry L. Morgan, eds., Papers from the Fifth Regional Meeting of the Chicago Linguistics Society. 252-286. Chicago Linguistics Society, University of Chicago, Ill.

Rouveret, Alain. 2006. VP ellipsis in phasal syntax: the case of Welsh. Ms, Université ParisDiderot and Laboratoire de Linguistique Formelle, CNRS.

Rouveret, Alain. 2011. Hallmarks of Portuguese syntax. In Laura Brugé, Anna Cardinaletti, Giuliana Giusti, Nicola Munaro and Cecilia Poletto, eds., A Festschrift for Guglielmo Cinque. Oxford: OUP.

Rouveret, Alain. 2012. VP ellipsis, the vP phase and the syntax of morphology. Natural 
Language and Linguistic Theory 30:3. 897-963.

Sag, Ivan. 1976. Deletion and logical form. Doctoral dissertation, MIT, Cambridge, Ma.

Sailor, Craig. 2009. Tagged for Deletion: A Typological Approach to VP Ellipsis in Tag Questions. Ma thesis, UCLA.

Sailor, Craig. 2012. Inflection at the interface. Ms. UCLA.

Sailor, Craig \& Grace Kuo. 2010. Taiwanese VP ellipsis and the progressive prohibition. Paper presented at $I A C L-18 \& N A C C L-22$, May 2010.

Saito, Mamoru. 2001. Genitive subjects in Japanese: implications for the theory of null objects. Paper presented at the International Symposium on Non-Nominative Subjects. Institute for the Study of Languages and Cultures of Asia and Africa. Tokyo University of Foreign Studies, December 2001.

Saito, Mamoru. 2004. Ellipsis and pronominal reference in Japanese clefts. Nanzan Linguistics 1. 21-50. Nagoya: Center for Linguistics, Nanzan University.

Saito, Mamoru \& Keiko Murasugi. 1990. N' deletion in Japanese. In Javier Ormazabel and Carol Tenny, eds., University of Connecticut Working Papers in Linguistics 3. 87-107. University of Connectitut, Storrs.

Saito, Mamoru. 2007. Notes on East Asian argument ellipsis. Language Research 43. 203227.

Sener, Serkan \& Daiko Takahashi. 2010. Ellipsis of argument in Japanese and Turkish. Nanzan Linguistics 6. 79-99.

Shinohara, Michie. 2006. On some differences between the major deletion phenomena and Japanese argument ellipsis. Ms., Nanzan University, Nagoya, Japan.

Shlonsky, Ur. 1991. Quantifiers as functional heads: a study of quantifier float in Hebrew. Lingua 84. 159-180.

Sportiche, Dominique. 1988. A theory of floating quantifiers and its corollaries for constituent structure. Linguistic Inquiry 19. 425-449.

Sugawa, Seichi. 2008. Ellipsis and repair effects. Nanzan Linguistics: Special Issue 3. 165183. Nagoya: Center for Linguistics, Nanzan University

Svenonius, Peter. 2004. On the edge. In David Adger, Cécile de Cat \& George Tsoulas eds., Syntactic edges and their effects. 261-287. Kluwer, Dordrecht.

Svenonius, Peter. 2005. Extending the extension condition to discontinuous idioms. Linguistic Variation Yearbook 5. 227-263.

Takahashi, Daiko. 2008a. Noun phrase ellipsis. In Shigeru Miyagawa and Mamoro Saito, eds., The Oxford Handbook of Japanese Linguistics. 394-422. New York: Oxford University Press.

Takahashi, Daiko. 2008b. Quantificational null objects and argument ellipsis. Linguistic Inquiry 39. 307-326.

Takahashi, Daiko. 2010. Argument Ellipsis, Anti-Agreement, and Scrambling. Ms., Tohoku University, Sendai.

Takita, Kensuke. 2011a. An argument for argument ellipsis from -sika NPIs. In Proceedings of the North East Linguistic Society 39, ed. by Suzi Lima, Kevin Mullin, and Brian Smith, 771-784. Amherst, MA: GLSA, University of Massachusetts.

Takita, Kensuke. 2011b. Argument Ellipsis in Japanese Right Dislocation. In Japanese/Korean Linguistics 18, ed. by William McClure and Marcel den Dikken, 380391. Stanford, CA: CSLI Publications.

Tancredi, Chris. 1992. Deletion, deaccenting, and presupposition. PhD Dissertation, MIT.

Taraldson, Tarald. 1984. Some phrase structure dependent differences between Swedish and Norwegian. Working Papers in Scandinavian Syntax 9. 1-45.

Thoms, Gary. 2011. Verb-floating and VPE: towards a movement account of ellipsis licensing. Linguistic Variation Yearbook 2011.

Thoms, Gary. 2012. Towarda a movement theory of ellipsis licensing. Paper presented at UiLOTS, Utrecht. 
Tomioka, Satoshi. 2003. The semantics of null arguments in Japanese and its cross-linguistic implications. In Kerstin Schwabe and Susanne Winkler, eds., Interfaces: deriving and interpreting omitted structures. 321-339. Amsterdam and Philadelphia: John Benjamins.

Verheugd, Els. 1990. Subject arguments and predicate nominals: a study of French copular sentences with two NPs. Amsterdam: Rodopi.

Warner, Anthony. 1986. Ellipsis conditions and the status of the English copula. York Papers in Linguistics 12. 153-172.

Williams, Edwin. 1984. There-insertion. Linguistic Inquiry 15. 131-153.

Wood, Winifred. 1979. Auxiliary reduction in English: a unified account. In P. R. Clyne, W. F. Hanks and C. L. Hofbauer, eds., Papers from the Fifteenth Regional Meeting. Chicago: Chicago Linguistics Society. 366-377.

Wurmbrand, Susi. 2012. Tense and aspect in English Infinitives. Ms. UConn.

Wurmbrand, Susi. To appear. QR and selection: Covert evidence for phasehood. In Stefan Keine and Shayne Sloggett, eds., Proceedings of the North Eastern Linguistics Society Annual Meeting 42. Amherst: University of Massachusetts, GLSA.

Zagona, Karen. 1982. Government and proper government of verbal projections. Doctoral dissertation, University of Washington.

Zagona, Karen. 1988. Verb Phrase Syntax: a Parametric Study of Spanish and English. Dordrecht: Kluwer. 